\title{
Nanodrug Delivery Systems for the Treatment of Ovarian Cancer
}

\author{
Jonathan M. Pantshwa, Pierre P. D. Kondiah $\mathbb{D}$, Yahya E. Choonara $\mathbb{D}$, Thashree Marimuthu $\mathbb{D}$ and \\ Viness Pillay *(D)
}

Wits Advanced Drug Delivery Platform Research Unit, Department of Pharmacy and Pharmacology, School of Therapeutic Sciences, Faculty of Health Sciences, University of the Witwatersrand, Johannesburg, 7 York Road, Parktown 2193, South Africa; monwabisi.pantshwa@wits.ac.za (J.M.P.); pierre.kondiah@wits.ac.za (P.P.D.K.); yahya.choonara@wits.ac.za (Y.E.C.); thashree.marimuthu@wits.ac.za (T.M.)

* Correspondence: viness.pillay@wits.ac.za; Tel.: +27-11-717-2274

Received: 4 November 2019; Accepted: 13 December 2019; Published: 15 January 2020

\begin{abstract}
Despite advances achieved in medicine, chemotherapeutics still has detrimental side effects with ovarian cancer (OC), accounting for numerous deaths among females. The provision of safe, early detection and active treatment of OC remains a challenge, in spite of improvements in new antineoplastic discovery. Nanosystems have shown remarkable progress with impact in diagnosis and chemotherapy of various cancers, due to their ideal size; improved drug encapsulation within its interior core; potential to minimize drug degradation; improve in vivo drug release kinetics; and prolong blood circulation times. However, nanodrug delivery systems have few limitations regarding its accuracy of tumour targeting and the ability to provide sustained drug release. Hence, a cogent and strategic approach has focused on nanosystem functionalization with antibody-based ligands to selectively enhance cellular uptake of antineoplastics. Antibody functionalized nanosystems are (advanced) synthetic candidates, with a broad range of efficiency in specific tumour targeting, whilst leaving normal cells unaffected. This article comprehensively reviews the present status of nanosystems, with particular emphasis on nanomicelles for molecular diagnosis and treatment of OC. In addition, biomarkers of nanosystems provide important prospects as chemotherapeutic strategies to upsurge the survival rate of patients with OC.
\end{abstract}

Keywords: nanosystems; drug delivery; nanomicelles; ovarian cancer; tumour targeting; chemotherapeutics

\section{Introduction}

Globally, ovarian cancer (OC) is a lethal condition that accounts for millions of deaths annually in females, making this condition a major health issue [1-6]. In the last five-year survey, statistics reflected approximately 21.9 million new patients clinically diagnosed with OC on a yearly basis, with 14,270 deaths predicted in the United States every year [7]. According to the World Health Organization (WHO), OC is one of the most lethal genital malignancies in females in developing countries, with this asymptomatic disease exacerbated by lack of early diagnostic strategies and access to expensive chemotherapeutic drugs [1]. In Africa (South Africa), the Cancer Council of Southern Africa (CANSA) confirmed more than 500 cases of OC [8]. Globally, the five-year survival rate ranges from $15 \%-20 \%$ for the population with advanced stage ovarian cancer, even though patients undergo operative surgery and platinum chemotherapy [9].

The treatment of OC employs invasive surgery for the removal of infected ovaries, uterus, fallopian tubes, cervix and lymph nodules in the abdomen. The surgical approach is followed by external beam radiotherapy or systemic chemotherapy, depending on the stage at which the OC disease is identified. Intravenous paclitaxel and alkylating cisplatin are conventional therapeutics employed 
for treatment of $\mathrm{OC}$ with antimetabolite methotrexate also considered as a possibility. However, conventional treatment has its own share of drawbacks, including toxicities and subsequent disease relapse, due to the development of multidrug resistance. In addition, the chemodrug is not specific for OC destruction, hence exhibiting dose cytotoxicity [10-12]. Furthermore, the long-term prognosis is usually adversative with expression and development of chemoresistant tumours. Patients undergo diverse side effects including excessive nausea, hair loss and deterioration in plasma cell counts linked with the administration of chemotherapy for OC treatment [13]. To circumvent treatment drawbacks of conventional antineoplastics, several targeted drug delivery platforms have been developed to direct antineoplastics to specific tumour sites [14].

New advances in polymeric nanotechnology—with particular emphasis on nanomicelles—provide feasible alternatives for early detection and targeted treatment of metastatic $\mathrm{OC}$, thereby minimizing systemic toxicity associated with administration of chemotherapeutic drugs. The nanosystems employed as theranostics include polymeric nanoparticles, nanomicelles, nanoconjugates, as well as dendrimers [14-16].

In order to improve diagnosis and chemotherapeutic efficacy in ovarian cancer treatment, this article presents a critique of, (a) formulation of nanoparticulate delivery systems (including nanomicelles), and (b) nanoparticulate delivery systems functionalized with ligands such as antibodies to expedite specific elimination of tumours, imaging analysis and aid in decreasing drug-related side effects (Figure 1). Thus, the basics of design of these delivery systems are to improve blood circulation in vivo, polymeric biodegradability, and theranostic compatibility with adequate retention time, for nanocarrier-related therapeutics. Furthermore, the synthetic building blocks of the carrier systems are nontoxic, noninteractive with inflammatory responses, and biocompatible. Other significant properties of polymeric carrier systems are biodegradability and clearance by hepatic/ renal pathways post-drug release, with the prospect to be further traced with additional benefits in molecular imaging technologies [17].

This review thus aims to present advances in nanosytems-based molecular diagnosis and treatment of OC. A particular focus is on nanomicelles as one of the most researched nanoarchetypes for imaging/diagnosis and targeted OC treatment. The status of OC biomarkers is concise, with the integration of studies conducted on mucins and possible application in early diagnostics and management of OC. These approaches are defined to potentially identify the disease at an early stage, halt disease progression and promote recovery.

\section{Current Nano-Based Drug Delivery Approaches for Ovarian Cancer Theranostic}

Numerous nanodrug delivery vehicles have been developed including nanoconjugates, branched dendrimers, liposomes, nanostructured lipid formulations and polymer nanomicelles (Table 1) [18,19]. These drug delivery systems have many advantages including the promotion of therapeutic drug delivery and fulfilling several (biopharmaceutical) parameters, such as a marked increase in therapeutic impact compared to the free drug, good biodegradability and biocompatibility, nontoxic and noninflammatory characteristics, as well as future prospects in scaling-up manufacturing [20]. In chemotherapeutic systems, a nanoformulation must possess high drug-loading capacity, the ability to dissolve drugs within the inner core and selectively accumulate in tumour tissue through permeability and retention influence (passive or active targeting). Targeted chemotherapy, such as intraperitoneal implantable treatment, provides targeted therapy within the peritoneal cavity (Figure 1) [21-25]. In addition, the preparation of nanoformulations functionalized with specific ligands facilitates preferential targeting of $\mathrm{OC}$ tumours and ultimately increases the therapeutic effect in comparison to nonfunctionalized nanosystems [25-30]. 
Table 1. Outline of the distinguishable nanotherapeutic tools designed for ovarian cancer treatment [19].

\begin{tabular}{|c|c|c|c|c|c|}
\hline Nanosystems & $\begin{array}{l}\text { Polymer-Drug } \\
\text { Conjugates }\end{array}$ & Dendrimers & Polymer Micelles & Liposomes & $\begin{array}{l}\text { Solid Lipid } \\
\text { Nanoparticles }\end{array}$ \\
\hline Size & $\leq 10 \mathrm{~nm}$ & $2-10 \mathrm{~nm}$ & $10-100 \mathrm{~nm}$ & $100-200 \mathrm{~nm}$ & $50-1000 \mathrm{~nm}$ \\
\hline $\begin{array}{l}\text { Structural } \\
\text { characteristics }\end{array}$ & $\begin{array}{l}\text { Macromolecular } \\
\text { structure }\end{array}$ & $\begin{array}{l}\text { Macromolecular } \\
\text { Tree-like } \\
\text { structure }\end{array}$ & $\begin{array}{c}\text { Spherical } \\
\text { Supramolecular } \\
\text { Core shell structure }\end{array}$ & $\begin{array}{l}\text { Spherical bilayer } \\
\text { vesicle structure }\end{array}$ & $\begin{array}{c}\text { Spherical, } \\
\text { bilayer-nanocapsular } \\
\text { structure }\end{array}$ \\
\hline $\begin{array}{l}\text { Carrier } \\
\text { composition }\end{array}$ & Water-soluble polymer & $\begin{array}{l}\text { Hyperbranched } \\
\text { polymer chains }\end{array}$ & $\begin{array}{l}\text { Amphiphilic di and } \\
\text { tri-block copolymers }\end{array}$ & $\begin{array}{l}\text { Phospholipid, } \\
\text { cholesterol } \\
\text { membrane lipids }\end{array}$ & $\begin{array}{l}\text { Solid lipid emulsifier } \\
\text { water }\end{array}$ \\
\hline \multirow[t]{2}{*}{$\begin{array}{l}\text { Drug } \\
\text { incorporation } \\
\text { strategy }\end{array}$} & $\begin{array}{l}\text { Covalent conjugation } \\
\text { requiring functional } \\
\text { groups on drug and } \\
\text { polymer }\end{array}$ & $\begin{array}{l}\text { Covalent } \\
\text { conjugation } \\
\text { requiring } \\
\text { functional } \\
\text { groups on drug } \\
\text { and polymer }\end{array}$ & $\begin{array}{l}\text { Noncovalent } \\
\text { encapsulation/ } \\
\text { compatible with } \\
\text { hydrophobic drugs }\end{array}$ & $\begin{array}{l}\text { Noncovalent } \\
\text { encapsulation/ } \\
\text { compatible with } \\
\text { hydrophilic drugs }\end{array}$ & $\begin{array}{l}\text { Noncovalent } \\
\text { encapsulation/ } \\
\text { compatible with } \\
\text { hydrophilic drugs }\end{array}$ \\
\hline & $\begin{array}{l}\text { PEG-paclitaxel \& HPMA } \\
\text { copolymer-doxorubicin- } \\
\text { phase II trials } \\
\text { SMANCS \& CDP870 } \\
\text { (Cimza)- Approved }\end{array}$ & $\begin{array}{l}\text { Dendrimer- } \\
\text { docetaxel \& } \\
\text { Viva gel- phase } \\
\text { II \& III trials } \\
\text { PSMA-targeted } \\
\text { dendrimers \& } \\
\text { Avidimer- } \\
\text { dendrimers- } \\
\text { Approved }\end{array}$ & $\begin{array}{c}\text { CRLX- } \\
\text { 101\&NKTR-102- } \\
\text { phase II/III clinical } \\
\text { trials } \\
\text { Genexol- PM- } \\
\text { Approved }\end{array}$ & $\begin{array}{l}\text { SGT53-01\& MCC- } 46 \\
\text { phase I clinical trials } \\
\text { Doxil, Ambisome \& } \\
\text { DaunoXome- } \\
\text { Approved }\end{array}$ & $\begin{array}{c}\text { SLNs with } \\
\left.\text { [Gd-DTPA }\left(\mathrm{H}_{2} \mathrm{O}\right)\right]^{2-} \\
\text { and } \\
{\left[\mathrm{Gd}-\mathrm{DOTA}\left(\mathrm{H}_{2} \mathrm{O}\right)\right]^{-}} \\
\text {compounds } \\
\text { preclinical trials [31]. } \\
\text { Diazemuls \& } \\
\text { Diprivan- Approved }\end{array}$ \\
\hline
\end{tabular}

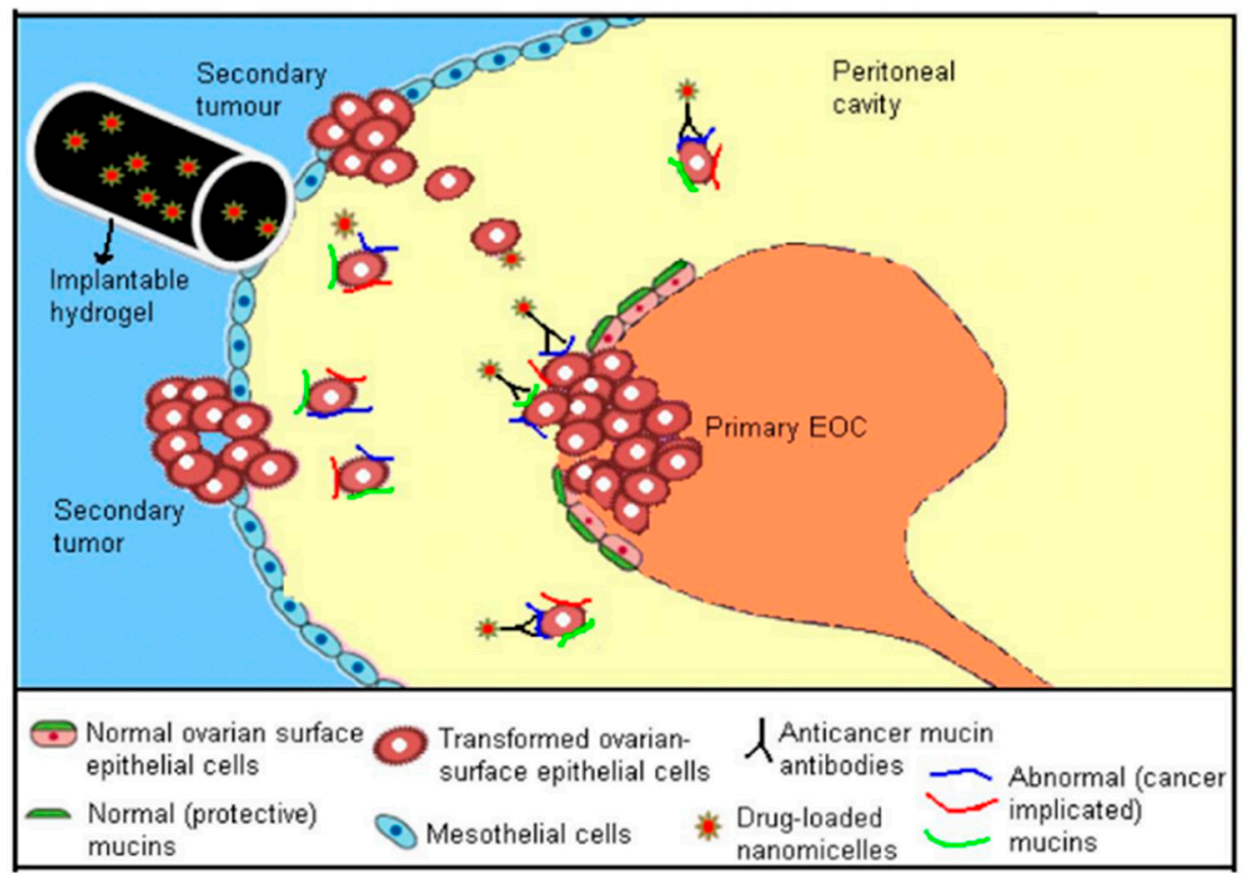

Figure 1. Illustration of the expression of cancer-associated mucins, accompanying the development of ovarian cancer and the intraperitoneal implant treatment, providing targeted therapy within the peritoneal cavity (Adapted with permission from [21].

In this context, there is a significant need to develop stable molecular biomarkers for early detection of OC [14]. Various prospective biomarkers of OC are reported. Epithelial ovarian tumours display modified cell antigens including, Human Epididymis Protein 4 (HE4 gene), Cancer Antigen 72-4(CA 72-4), Renal Estimated Glomerular Filtration Rate (EGFR), Soluble Mesothelin-Related Peptides (SMRP), Mesothelin, Osteopontin (OPN), Alpha-Fetoprotein (AFP), Cytotoxic T-Lymphocyte-associated Protein 4 (CTLA4), Interferon-alpha (IFN $\alpha$ ), Kallikrein-6 (KLK6), phospholipase A2 group 2A (PLA2G2A), Erythroblastic Oncogene B2 (ErbB2), Interleukin-10 (IL-10) and Mucin-16 (MUC1-16), that differentiate cancerous cells from healthy ovarian tissue and other ordinary cells covering the 
intraperitoneum [23-30]. Mucin proteins (specifically MUC16) show prospective as biomarkers and antibody functionalized micelles to provide a broad range of prospects for OC therapy [32].

Nanomicelles are synthetic nanovehicles, with high potential loading capacity for chemotherapeutics designed for site-specific ovarian tumour targeting [33-36]. A size range of a micelle between 10-100 nm promotes significant permeability, endocytosis by OC cells and decreases nonselective targeting of normal cells [37]. Nanomicelles can perforate and assemble in regions with permeated vasculatures, including tumours and inflamed tissues [37-39]. In addition, improved biocompatibility, in vivo stability, ability to incorporate a wide range of hydrophobic chemotherapeutics, as well as extended plasma circulation periods, are achieved [40,41].

\section{Critical Comparison of Nanosystems to Nanomicelles for OC Treatment}

Polymer-drug conjugates or prodrugs are macromolecular dispersed systems that require covalent binding of the active principle while nanoparticles on the contrary are physically attached to the active principle. Polymer-drug conjugates have low molecular weight (specific to polymer incorporation), which permits molecular targeting within the cancer cell $[42,43]$. Physicochemical properties of polymer-drug conjugates $\left(\mathrm{pH}\right.$, enzymatic-alteration, acid $\left(\mathrm{H}^{+}\right)$-catalytic chemical reactions) are vital for drug release at a tumour site. Polymer-drug conjugates are extensively evaluated for prolonged drug release in cancer cells, tumour mass invasion, and enhancement of anti-tumour proliferation [44-46]. Therapeutics in ovarian cancer also utilize branched dendrimers formulated from several polymers and genetic DNA, however acrylamide branched nanodendrimers are usually utilized [46]. Branched dendrimers have characteristic design components including (i) peripheral surface with several potential attachment sites, (ii) the central inner core where diverse dendrons demarcate the alienated constituent stratums covering the inner core and (iii) the location for dendronic conjugation. The three fragments of branched dendrimers are modified for several uses, including drug transport and DNA delivery [47]. Polymer-drug conjugates and dendrimers have covalently bonded drug molecules to the polymeric carriers. This consecutively necessitates the association of the complex with specific biochemical processes, shielding the complex from in vivo catalytic enzymatic destruction and protonic acid-hydrolytic reactions [48-50]. Furthermore, the minute-size of these carriers (normally $10 \mathrm{~nm}$ ), enables perforation through plasma membranes of the glomeruli [17]. Significant assemblies and differentiating properties of these delivery systems are demonstrated in Table 1, as well as in Figure 2.

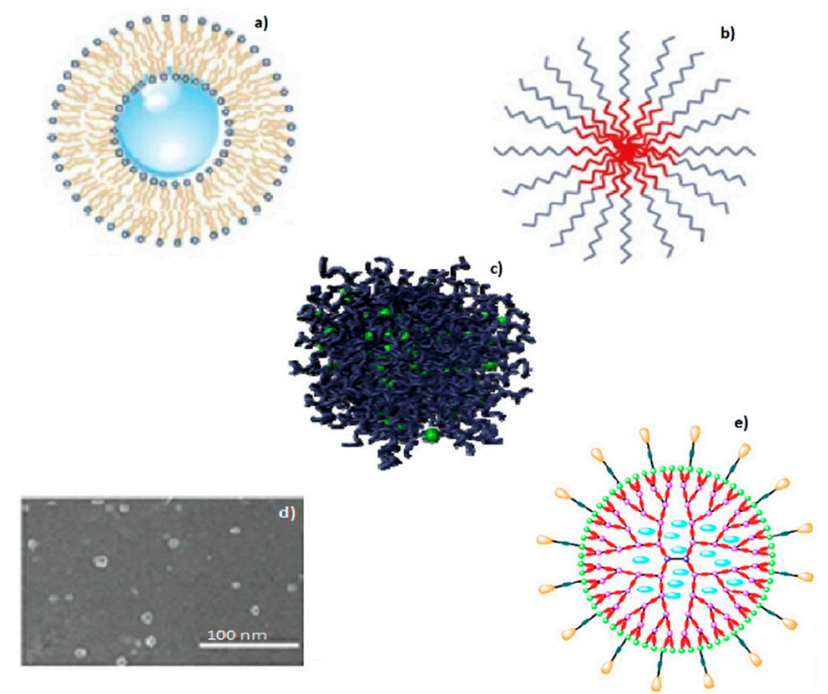

Figure 2. Schematic depicting examples of nanosized delivery systems; (a) liposomes, (b) nanomicelles, $(\mathbf{c}, \mathbf{d})$ polymer-drug conjugates, and (e) dendrimers, which are currently explored in detail for transport of chemotherapeutic agents (adapted with permission from (a) Trucillo et al. [31], (b) Brandta et al. [51], (c,d) Tong et al. [52], (e) Huang \&Wu [53]. 
Liposomes are similar to nanomicelles due to microscopic spherical shape, consisting of a lipid bilayer, encapsulating aqueous components for hydrophobic drug incorporation. Nonpolar lipophilic drugs are incorporated within the lipid bicoating, while water-soluble drugs reside in the vesicle. Entrapment of antineoplastic therapies in lipophilic liposomes result in pharmacokinetic modifications and pharmacodynamics features, with a resultant decline in drug degradation and improved dose cytotoxicity [31,51-53]. These lipophilic nanocarriers can be utilised for specific targeting and imaging of tumour tissues; however, ligands applied to the phospholipid coating improve cellular uptake thus enabling a pronounced therapeutic effect to the targeted specific-sites [31,51-54]. Solid lipid nanoparticles (SLNs) also have similar properties to nanomicelles. On the contrary, the major challenges with liposomes include instability and difficulty in large-scale synthesis.

Poorly water-soluble drugs are encapsulated in the hydrophobic interior of SLNs, but the distribution ability is hindered by membrane destabilization. However, most liposomal and SLNs are above $90 \mathrm{~nm}$ in size, due to intrinsic structural parameters which significantly restrict delivery to ovarian tumour tissue. To surmount the setbacks associated with liposomes and SLNs, other nanoplatforms, including nanoemulsions, polymeric nanoparticles and polymeric nanomicelles are employed [19].

Nanoemulsions are used as templates for polymeric nanoparticle preparation. Therapeutic-loaded nanoemulsions are formed by oil-in-water $(\mathrm{o} / \mathrm{w})$ solvent evaporation techniques, employing miscible organic solvents (diethyl ether, chloroform, N, N-dimethylformamide (DMF), acetonitrile, THF). Simple liquid emulsions are either oil-suspended in an aqueous state $(\mathrm{o} / \mathrm{w})$, or water-suspended in oil (w/o). Nanoemulsions are aqueous emulsions with sizes normally between 20-200 nm. Nanoemulsions are formulated employing low-energy emulsification procedures, in which the nanosize is adjusted by the physicochemical parameters of the process [55], allowing the development of small-scale and homogeneous droplets, employing a high-energy system, in which a nanosized droplet is adjusted by the degree of the peripheral energy contribution. Among the low-energy emulsification approaches, the Phase Inversion Composition (PIC) system is highly beneficial for structures with thermo-labile composites, including therapeutics, as it can be accomplished at ambient temperature. In the PIC system, the emulsification process is activated by the variations in the voluntary amphiphilic curvature generated in emulsification, changing the constituent at stable temperatures [55].

\section{Morphology, Composition and Mechanism of the Formation of Nanomicelles}

Nanomicelles are spontaneously self-assembled or aggregated as versatile nanoparticles formed in water at certain physicochemical parameters including concentration (above Critical Nanomicelle Concentration-CNC), temperature and conductivity; employing surfactants (hydrophilic-hydrophobic polymers), with opposite affinities towards a particular solution [55]. The assembly of amphiphilic components generates the structure or shape of nanomicelles. The copolymer sequence controls the configuration of the prepared nanomicelles. Thin rod designed nanomicelles are also generated when the water-insoluble component is greater than the water-soluble component. Sphere-shaped nanomicelles are usually indicative of a longer hydrophilic component with a minor hydrophobic component, or possibly a result of equal degrees of the amphiphilic components [56]. Constituents of the prepared supramolecular structure of polymeric micelles are usually di- or tri-segment/block, or a stable copolymer (Figure 3). Poly (ethylene oxide) (PEO) forms a barrier to nanomicelles, collapsing and displaying dissolution in an aqueous solvent $[33,57]$. The inner central component normally possesses a biodegradable polymer such as $\mathrm{PEO} / \beta$-amino polyesters that can be utilised as an inner core to dissolve hydrophobic pharmaceutical drugs, thus shielding loaded constituents from the aqueous environment; increasing the bioavailability and in vivo efficacy [58-60].

At low ratios in aqueous media, copolymers exist separately, however, once the molar concentration is increased, aggregation occurs [61]. The aggregates known as nanomicelles, comprises of several copolymers in a spherical arrangement $[62,63]$. When attachments to the polymer functional groups 
are anticipated, complexes including carboxylic $\left(\mathrm{COO}^{-}\right)$conjugate bases and amine $(\mathrm{NH})$ bases are joined as the sequence terminating clusters [33].

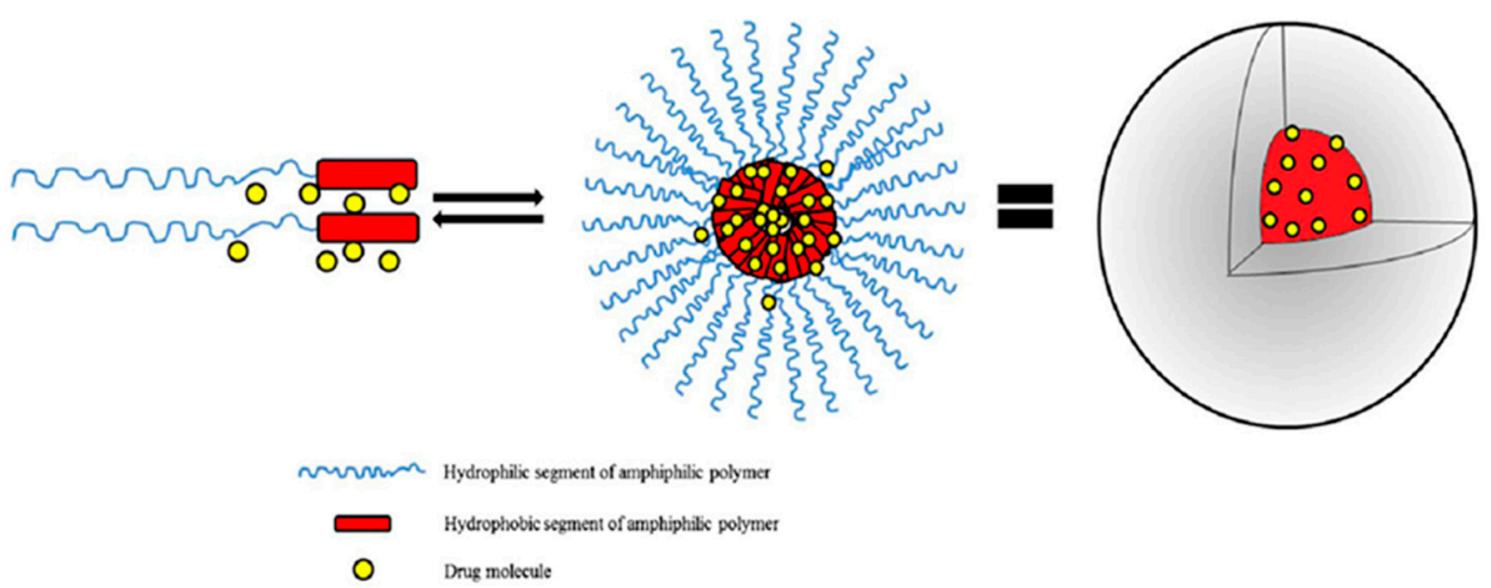

Figure 3. Schematic representation of the supramolecular structure of polymeric micelles (adapted with permission from Lu and Park [47]).

\section{Classification of Nanomicelles}

Nanomicelles are classified into three key distinct nanosystems i.e., colloidal nanomicelles formulated from an aggregation of polar and nonpolar molecules in an aqueous solution (amphiphilic aggregates), polyionic nanomicelles formulated from oppositely charged polymers generating an agglomeration due to electrostatic interaction, and nanomicelles originating from metal complexation [63-66].

\subsection{Amphiphilic Nanomicelles}

Amphiphilic colloidal nanomicelles are formed from hydrophobic interactions between the inner core and the outer shell of the surfactant molecules in a solution [60]. An active surfactant retains amphiphilic configurations, comprised of hydrophobic and hydrophilic functional groups [66]. The hydrophilic groups form the polar clusters constructed from several moieties including ionised carboxyl, conjugated sulfonate, ammonium, active hydroxyl and amides. Hydrophobic clusters are nonpolar ends, including molecular hydrocarbon chains with eight or additional carbon molecules, and can be rectilinear or separated structures. Lipophilic and hydrophilic polymers self-assemble into nanomicelles with adequate surfactant concentration. The resultant concentration of surfactant for the formation of nanomicelles is known as critical micelle concentration (CMC). Figure 4 depicts the settings of surfactant alignment on air/aqueous interface to form nanomicelles when subjected to a particular solution with opposite charge affinities to hydrophobic and hydrophilic molecules. The polar ends form the outer surface of nanomicelles with the nonpolar portions, establishes the inner central core. The quantity of drug incorporated into copolymeric nanomicelles is influenced by physicochemical parameters that result in hydrophobic interactions between the drug and the hydrophobic segment of the polymers. Hence, a consideration of physicochemical trends is an invaluable tool in the synthesis of drug loaded copolymeric nanomicelles. The amphiphilic block copolymer, Pluronic ${ }^{\circledR}$ poloxamer, generates amphiphilic nanomicelles in response to electrostatic interactions [63,67]. 


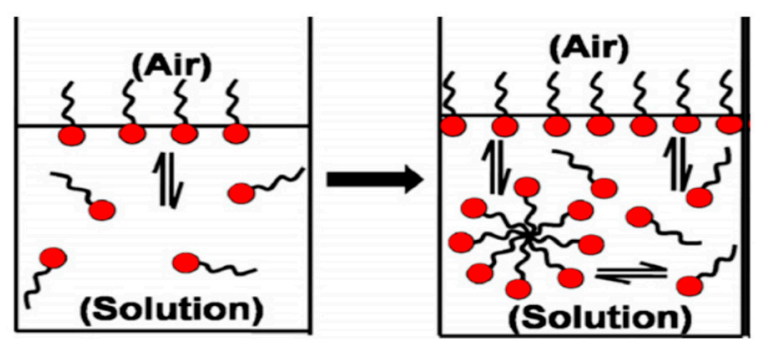

Figure 4. Schematic depiction of surfactant molecules aligning on water/air interface at preand post-'Critical Nanomicelle Concentration (CNC)' threshold (adapted with permission from Mukherjee et al. [68]).

\subsection{Polycharged Composite Nanomicelles}

Polycharged complex nanomicelles (PCCMs) are formulated by the self-assembly of oppositely charged polymers that form aggregates when distributed in an aqueous solution by hydrophilic groups, usually poly(ethylene glycol) (PEG), and are covalently attached to one of the two ionic polymers. Electrostatic interactions are the intermolecular cohesive forces of the assembled composite; with electrostatic and hydrophobic exchanges employed in formulated nanomicelle complexes. PCCMs are prepared using various synthetic methods, including common synthetic procedures and spontaneous self-assemblage or aggregation in solution. PCCMs are prepared from segment copolymers in an aqueous solution, thus circumventing associated cytotoxicity of organic solvent. These nanomicelles are stable with low CMC values-as low as $10^{-6} \mathrm{M}$. The central core of PCCMs encapsulates several therapeutics, such as hydrophilic and hydrophobic drugs employing intermolecular cohesive forces and hydrogen bond interactions. Therapeutics such as cisplatin and ionic large-scale drugs are released from PCCMs, subsequent to induction from appropriate stimuli [68].

\subsection{Noncovalent Connected Polymeric Nanomicelles}

These nanomicelles are prepared to employ homopolymeric material or monomer units for nanomicelle agglomeration. The inner and the outer surface are bonded at the polymer edges via specific intermolecular interactions including hydrogen bonds or metal coordinate bonds; for this reason, are known as noncovalently linked nanomicelles. Poly (4-vinylpyridine) functionalized with carboxyl-terminated polybutadiene are the mainstay of intermolecular interaction due to the formation of hydrogen linkages in a common organic solvent such as chloroform [63].

\section{Surfactants Employed in Nanomicelle Targeted Platforms for Ovarian Cancer}

Surfactant nanomicelles utilized for drug delivery have hydrophobic esters, including polypropylene oxide (PPO), poly(L-lactide) (PLA), poly(D,L- lactide) (PDLLA), as well as amino functional groups such as poly lactide-co-gycolide (PLGA), polycaprolactone (PCL), poly ( $\beta$-amino ester), and polylactic acid (PLA) in their inner core segment for dissolving hydrophobic chemotherapeutics, as illustrated in Table 2. The hydrophobic core segment is compatible, nontoxic, biodegradable and permitted by the U.S. Food and Drug Administration (FDA) for biopharmaceutical application. On the contrary, the soluble hydrophilic corona surface of the nanomicelle used in therapeutic release is composed of poly(ethylene glycol) PEG, poly(ethylene oxide) PEO, poly N-vinyl pyrrolidone (PVP), poly N-isopropyacrylamide (PNIPAM), poly $\mathrm{N}$-vinyl alcohol (PVA), and poly N-2-hydroxyproyl methacrylamide (PHPMAm), as displayed in the first section of Table 2. In this context, the surfactants self-assemble to form micelles in an aqueous solution with the central amino or ester section, which is structurally neutral/uncharged and connected to the hydrophilic corona. Protein copolymers (including drug peptide copolymers) employed in chemotherapeutic delivery enhance the accumulation at pathological sites and improve endocytotic uptake into the tumour cells. Modification of a specific sequence of the amino acid alters enzymatic functioning and the degree of immune system response [53]. 
Table 2. Building block copolymers employed in micelle drug transport nanosystems (adapted from Sutton et al., 2007) [69].

\begin{tabular}{|c|c|c|}
\hline Copolymers & Abbreviation & Repeating Unit Structure \\
\hline \multicolumn{3}{|l|}{ Corona segment } \\
\hline Poly (ethylene glycol) & PEG, PEO & \\
\hline Poly (N-vinyl pyrrolidone) & PVP & \\
\hline Poly (N-isopropyacrylamide & PNIPAM, NIPAM & \\
\hline Poly (N-vinyl alcohol) & PVA & \\
\hline Poly (N-(2-hydroxyproyl methacrylamide) & pHPMAm & \\
\hline \multicolumn{3}{|l|}{ Core segment } \\
\hline \multicolumn{3}{|l|}{ Polyesters } \\
\hline Poly (propylene oxide) & $\mathrm{PPO}$ & \\
\hline \multicolumn{3}{|l|}{$\begin{array}{c}\text { Poly esters } \\
\text { Poly (L-lactide) }\end{array}$} \\
\hline Poly (D,L-lactide) & PLA, PDLLA & \\
\hline Poly (lactide-co-gycolide) & PLGA & \\
\hline Poly ( $\epsilon$-caprolactone) & PCL & \\
\hline \multicolumn{3}{|l|}{ Poly $(\beta$-amino ester $)$} \\
\hline Poly(lactic acid) & PLA & \\
\hline
\end{tabular}




\section{Preparation of Drug-Loaded Nanomicelles for Application in Ovarian Cancer}

Preparation of therapeutic-loaded nanomicelles involves two major categories of therapeutic loading, reliant on the physicochemical properties of a block copolymer (Figure 5) [69]. The first category is the dissolution of co-polymer with a drug in a solution. This method is used in insoluble polymers, including Pluronics poloxamers, and necessitate the warming of the solution for nanomicelle aggregation, utilizing the dehydrated core profiling portion. This dissolution technique is also employed in preparation of PCCMs, with therapeutic polymer dissolved separately, and nanomicelle aggregates impelled by mixing of the two solutions to stabilize therapeutic-polymer ionic proportions [70,71]. The drawback of this technique is the low drug loading that occurs in nanomicelles [60,72].

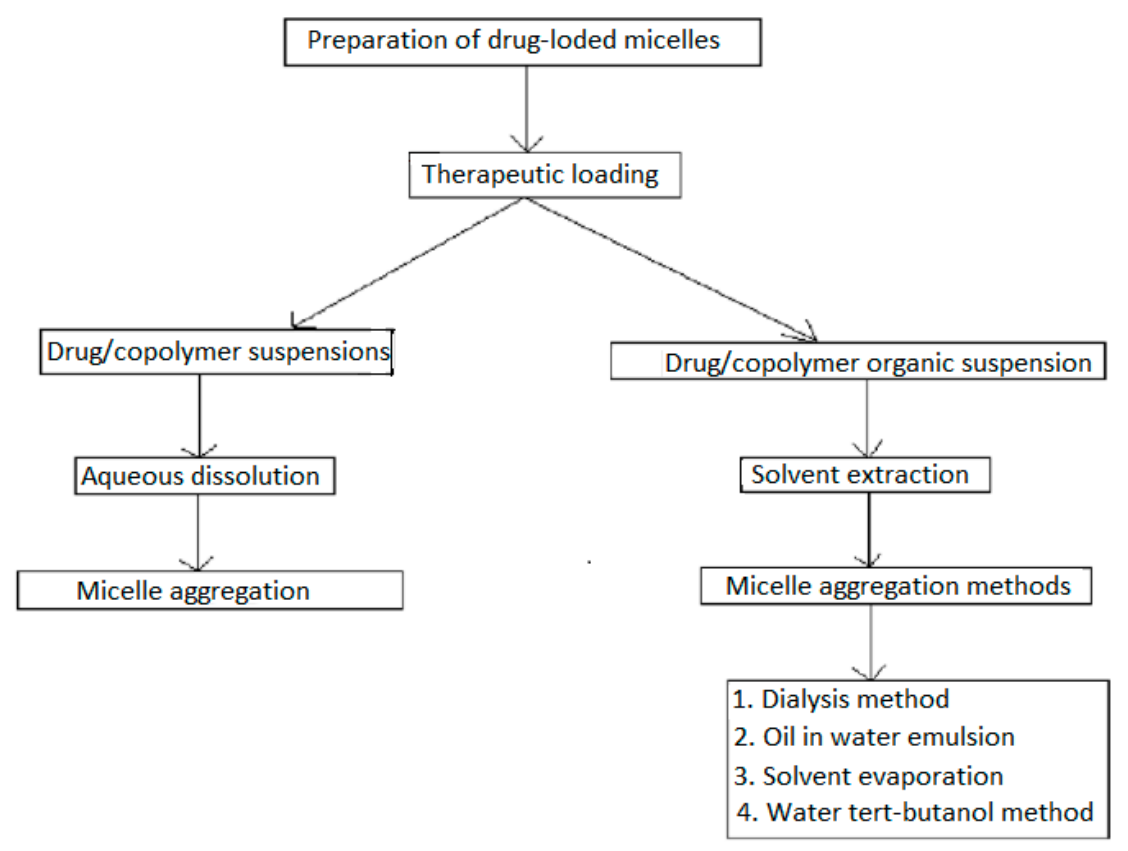

Figure 5. Commonly employed methods of drug-loaded micelle preparation.

The second method of therapeutic loading involves the surfactant, which are partially water-soluble and for which an organic solvent (such as, tert-butyl alcohol, ethyl acetic acid, methyl alcohol, toluene, dichloromethane (DCM), aprotic diethyl ether and chloroform/trichloromethane) is required to dissolve the polymer and therapeutic [73]. Nanomicelle aggregation is reliant on the liquid extraction technique. For homogenous solutions, nanomicelle formulations are extracted via a dialysis exchange method, with slow extraction of the organic solvent that activates nanomicelle aggregation. A drawback of the dialysis technique is that the dissolving of a drug-polymer involves the use of chlorinated solvents, which are toxic and thus necessitate extra time $(<36 \mathrm{~h})$ for the adequate encapsulation of therapeutics into the nanomicelles. Alternatively, the solvent-evaporation technique is utilized for the removal of organic solvents by air diffusion to form a polymeric film. The introduction of water to the film with heating facilitates the aggregation of drug-loaded nanomicelles. Nanomicelles synthesized from solvent-evaporation technique have increased potential of dissolving high quantities of partially soluble drugs. These methods all require sterilization and freeze-drying stabilization processes for preservation of the synthesized formulations. Figure 5 depicts the drug loading techniques for nanomicelle formulation.

The limitations in preparations of therapeutic-loaded nanomicelles are surmounted by employing improved approaches such as the tert-butanol (TBA) method, which incorporates the solution of copolymer and therapeutic liquid/TBA medium followed by freeze-drying, to form a dry powdered lyophilized cake. Stable nanomicelles spontaneously self-aggregate, upon resuspension of the lyophilized powdered polymer-therapeutic cake in an aqueous solution [74,75]. 


\section{Applications of Nanomicelles in Ovarian Cancer}

Nanomicelles are considered as prospective carriers for imaging agents and therapeutics due to their extended circulatory times, improved drug stability, specific targeting and proliferation into tumour tissue. Nanomicelles are employed as multifunctional molecular probes for identification (diagnosis), noninvasive screening and early treatment of ovarian cancer [72].

\subsection{Diagnosis of Ovarian Cancer Employing Nanomicelles}

Ovarian carcinoma is commonly identified in late stages due to comparative lack of early detection and diagnostic techniques in early stages [44]. The delivery and controlled release of therapeutics for site-specific targeted chemotherapy and imaging for early cancer identification are of great pertinence $[76,77]$. Imaging involves visualization of OC disease development, treatment efficacy and bio-distribution of therapeutics to the tumour, or investigation of molecular biomarkers [78]. Disease inspection and monitoring of therapeutic efficiency can be achieved by employing current medical visualizing modalities such as basic radiography, anatomical probes (CT scanning), ultrasound and magnetic resonance imaging (MRI) [74].

These imaging techniques can be categorized according to the energy utilized to develop visual images (heterogeneous $\mathrm{X}$-ray beams, positron emissions, photon emissions), spatial specific resolution accomplished (macroscopic-, meso-scale, microscopic), or the nature of the captured information (anatomical, physiological or molecular/cellular imaging) [44,75]. However, these imaging techniques rely on a diagnosis of cancer when tumours have developed to approximately $1 \mathrm{~cm}^{3}$, and at this stage, the malignancy has around 1 billion metastatic tumour cells [79]. Furthermore, imaging probes have low signal transmission, instability, imprecise interactions, and rapid degradation from the circulatory system [80].

Nanotherapeutic applications incorporating noninvasive tumour molecular imaging have prospects in early prognosis by increasing the precision, efficacy of chemotherapeutics, and facilitating improved infection detection [44]. If image modalities are utilized to image tumours, improved tumour intensity is assimilated with contrast nanocarrier systems. Nanoparticles have distinct techniques for molecular-targeted delivery, drug encapsulation, or improvement of pathological areal imaging. Polymeric nanoparticles, including PEG-b-poly(Lysine) copolymers have great potential in analytic molecular imaging, monitoring of cancer development or regression [44]. Small particles within nanometer range, such as gold-plated-based molecules and coated metallic quantum molecules, are the most usually employed; however, other nanoparticles and biomarkers display possibilities as potent tools for potential transmission development and therapeutic delivery in diagnosis of infected sites [44]. Various one-off administered nanomicelle-based therapeutic delivery systems for tracking and targeting of ovarian cancer are outlined in Table 3. 
Table 3. Polymeric micellar systems employed for treatment and diagnosis (adapted from Kedar et al. [80]; Chen et al. [81]).

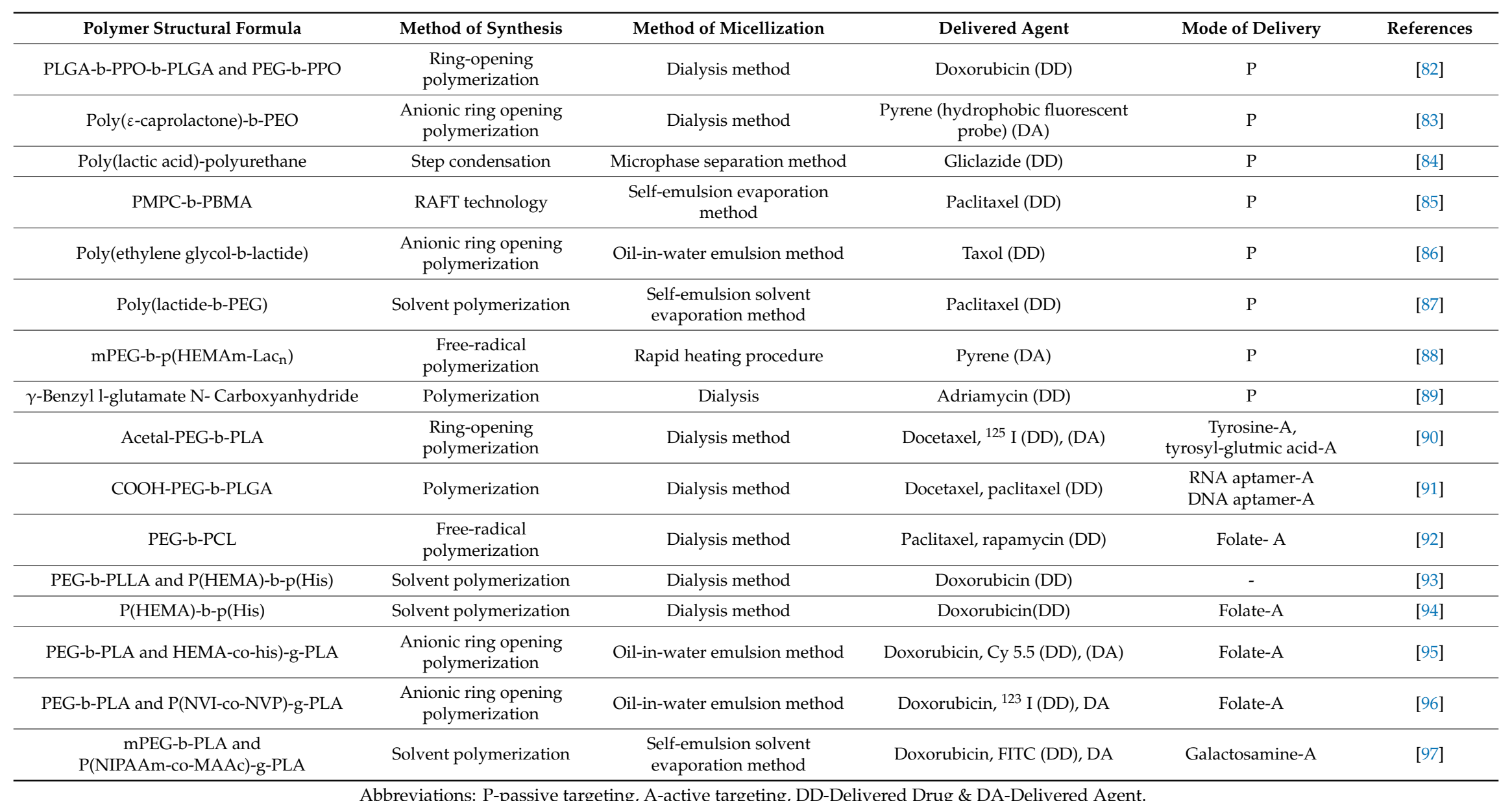


Several nanomicellar technologies have been established and are presently undergoing extensive preclinical and clinical trials for application in chemotherapeutics and diagnostic imaging of ovarian cancer. Amphiphilic block-copolymers aggregate to form dual-layered nanomicelles and are future carriers of hydrophobic treatments and diagnostic probes. Partially soluble drugs and imaging agents are encapsulated into the inner core with hydrophilic surface of amphiphilic nanomicelles, forming a stable outer shell in an aqueous solution [77].

Diagnostic modalities for three main imaging probes are radioactive metals, including indium-111 ( $\left.{ }^{111} \mathrm{In}\right)$, and radioactive metal complexes such as ortechnetium-99 $\mathrm{m}\left({ }^{99 \mathrm{~m}} \mathrm{Tc}\right)$, used for scintigraphy; clustered/chelated magnetic metals, including gold, for magnetic resonance imaging (MRI); and iodine for conventional X-ray computed tomography (CT). The conventional contrast agents employed in medical therapeutics are low-molecular-weight complexes composed of these chemical probes. Several diagnostically significant amphiphilic composites have been effectively integrated into nanomicelles, including diethylene-triamine penta-acetic acid (DTPA), which are chelating agents for diagnostic imaging of various nanomicellar platforms utilized in MR diagnostic imaging. Polymeric nanomicelle systems, including iodine-containing PLL-PEG nanomicelles, are employed for cancer diagnostic imaging, utilizing conventional sectional tomography (CT) imaging and Single Photon Emission Computed Tomography SPECT using gamma rays. Furthermore, to monitor nanomicelles formulations and exchanges in cancer disease, nanomicelle co-encapsulated with imaging clustered/chelated metallic groups have been employed, for example, in gold compounds, manganese oxide-loaded nanoparticles, as well as being utilized with ultrasound (US) and magnetic resonance imaging (MRI) [76]. Currently, gadolinium $(\mathrm{Gd})$-contrast medium, including Magnevist ${ }^{\circledR}$, are medically employed where visual contrast is increased by limiting the T1 reduction period (period of high longitudinal magnetization with brighter image) of aqueous protons. Integration of $\mathrm{Gd}$ compound on the nanomicelles' surface upsurge the T1 reductivity and reactivity of diagnosis. The reactivity is improved by utilization of various developed architectural iron oxide nanoparticles such as surface designed Super Paramagnetic Iron Oxide Nanoparticles (SPIONS) that assemble in nanomicelle inner core and exhibit MRI reactivity at a nanomolar rate. Nanomicellar loading with therapeutics and imaging tools such as fluorescence Rhodamine and FITC probes are used for drug released imaging at specific tumour sites with distinctive designed image. Hence, nanomicelles are favourable as carriers for combinational chemotherapeutics and nanodiagnostic tools [98-100].

\subsection{Treatment of Ovarian Cancer Using Nanomicelles}

Nanomicelles are mainly administered intravenously (IV) and are usually exposed to several challenges of the blood circulatory system with resultant cytotoxicity before reaching the peritoneal cavity [101]. The intraperitoneal (IP) cavity is the principal site of OC disease [102]. Metastatic OC cells accountable for high mortality rate disseminate and recur at the intraperitoneal site [103]. Hence, IP nanomicellar chemotherapy is the favorable route of administration of OC treatment, with improved patient compliance as compared to intravenous (IV) treatment [104-106].

\subsection{Targeting Strategies of Nanomicelles}

Targeted delivery of polymeric nanomicelles loaded with chemotherapeutic agents, present many diverse advantages [107]. Targeting is usually achieved using two delivery mechanisms as depicted in Figure 6; (i) passive targeting with improved vascular permeability and absorbency effect [39], (ii) specific active receptor-mediated targeting, employing ligand functionalized-nanomicelles, including the attachment of antibodies [63]. 

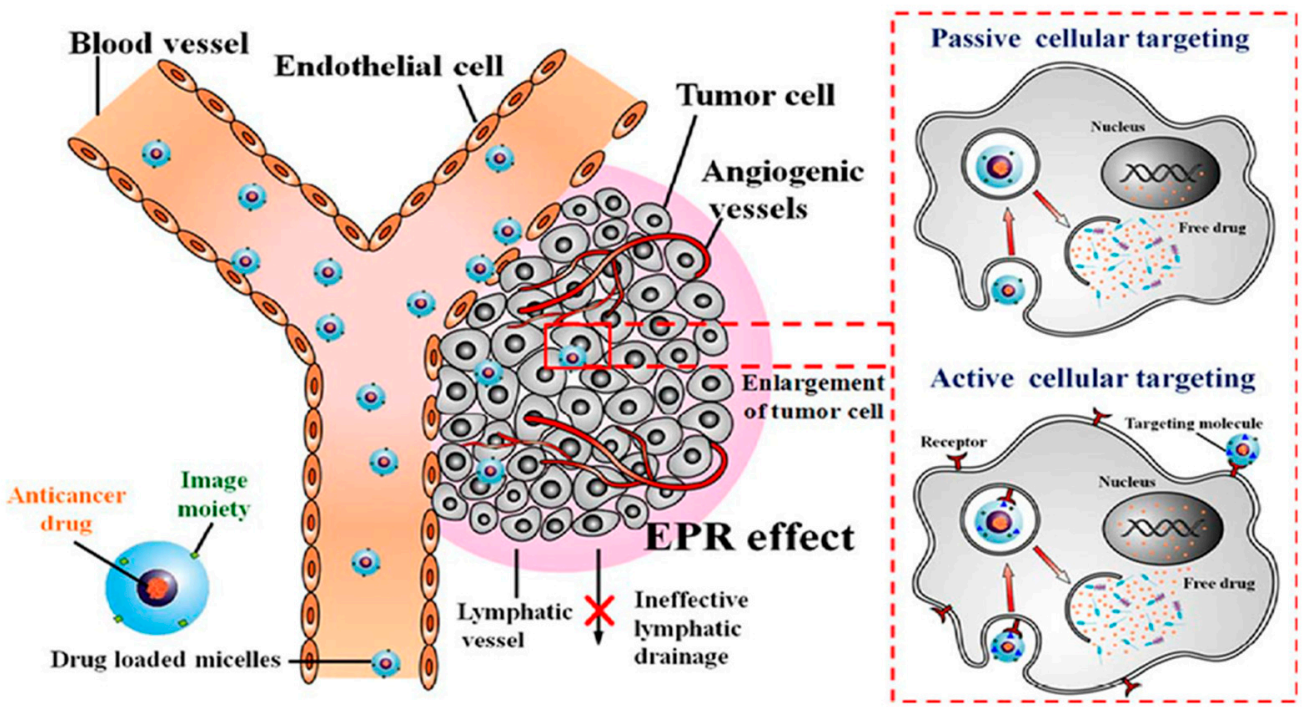

Figure 6. Schematic representation of drug loaded micelles (spheres) with imaging agents, from the administration site to the tumour tissue. After administration, micelles (10-200 nm) display specific targeting of tumour growth via passive targeting with cellular endocytotic uptake from exterior fluid to the cancer cells. Active targeting through receptor-mediated internalization is achieved by attachment of antibody ligand molecules, to the surface of micelles (Adapted with permission from Chen et al. [81]).

\subsubsection{Passive Targeting by Enhanced Permeability Effect of Tumour Tubular Blood Vessels}

When nonfunctionalised nanomicelles have significant continual blood circulation period and successfully accumulate in tumour tissue through the passive enhanced permeability effect (EPR), this is indicative of passive targeting $[76,108]$. The therapeutic payloads are distributed to the tumour extracellular matrix and dispensed into the tumour cells and tissues. EPR targeting is ascribed to pathophysiological properties of tumours that are not identified in health tissue. These properties include the architecture of leaky tumour blood vasculature, impaired lymphatic drainage scheme, and increase in formation of permeability agents [109-112]. Several passive targeting nanocarrier systems have a PEG coating for stealth and "concealment" properties, including Genexol-PM, SP1049C, NK911, Opaxio $^{\mathrm{TM}}$ (formerly Xyotax ${ }^{\mathrm{TM}}$ ), CRLX101, ProLindac ${ }^{\mathrm{TM}}$, SPI-77 and CPT-11 [76].

\subsubsection{Specific Active Receptor-Mediated Targeting}

The active targeting approach involves the attachment of functional ligands to the nanomicelle surface. These ligands identify tumour-specific receptors that are overexpressed on the cancer cell plasma membranes, resulting in increased uptake and increased internalization of nanomicelles into tumour tissue via the receptor-mediated endocytosis process [113-115]. Commonly utilized affinity ligands are classified into the following categories: small unrefined molecules, nucleotides (RGD sequence), oligopeptides, sugar groups, folates, monoclonal antibodies ( $\mathrm{mAb})$, and nucleic DNA/RNA aptamers [116].

There are several tools that are being utilized to target particles to tumour tissue. The use of an activating ligand is a dynamic approach that is reliant on specific receptors at an attachment site. These interactions include (glycoproteins/antibody), antigens and activating attachment groups (Figure 7). The "magic bullet concept" Ehrlich hypothesized that antibody-bounded nanocarriers have progressed into a model using three components: a therapeutic, a copolymer and active functionalizing agents associated with one formulation. This targeting therapeutic strategy provides rewards, including high target specificity for the pathological/infected area and minimal toxicity to the healthy cells. Furthermore, this therapeutic strategy also improves tumour treatment, chemotherapeutics of metastatic cancer of early stage carcinoma, when the primary papillary fallopian tubes are still immature [113-115]. 


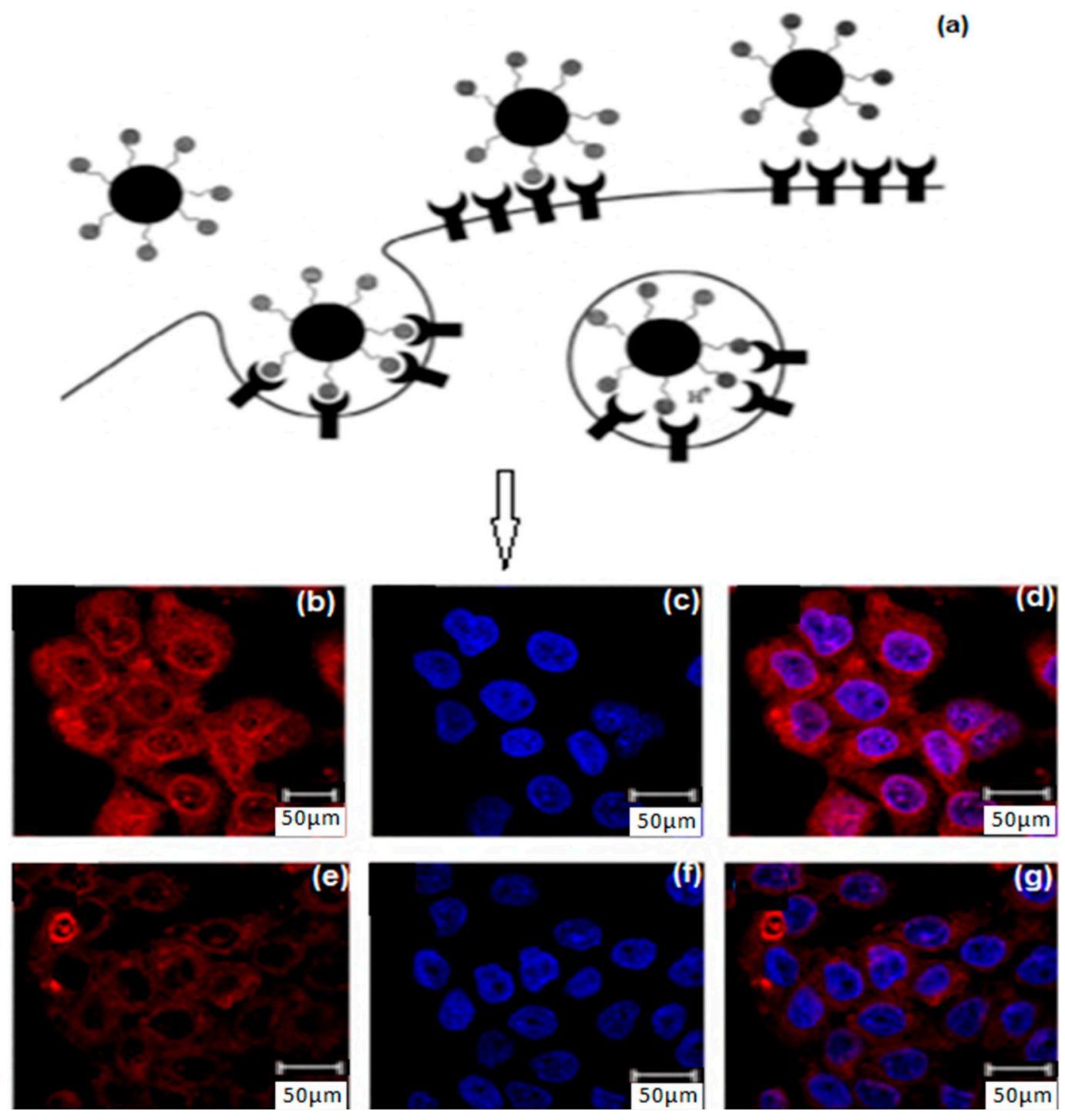

Figure 7. Schematic depiction of (a) active targeting, (b-g) confocal images of A431 cellular uptake incubated with cetuximab encapsulated micelles and lysotracker. The fluorescence intensity of A431 cells (b-d) treated with targeting micelles was 1.45 times higher than in cells incubated with antibody-free micelles (e-g) (Adapted with permission from Sudimack et al. [117]; Liao et al. [118].

\section{Mucins as Targets for Antibodies in Chemotherapeutics}

Most ovarian carcinomas are of epithelial origin and express mucins utilized as prospective diagnostics and treatment targets. Mucin glycoproteins are extracellular, glycosylated protein molecules, originating in the mucus coating and increased expression has been linked with various types of malignant pathology including OC. Currently, there are 20 identified mucins with two classifications: epithelial mucins (gelating, nongelating, film attached mucins) and lycoproteins (MUC9, MUC10, MUC18 and MUC20) [116-118]. Various research studies on the expression of mucin antigen in ovarian cancer have identified overexpression of film-attached mucins, especially MUC4, MUC5AC, and MUC16, but their biological applications are not defined. Mucin 16 (CA125) is used as a clinical biological marker in OC due to its elevated expression which results in CA125 release into the blood serum $[119,120]$. CA125 is a very huge cell surface mucin, first established by Robert Knapp in 1981. He identified this glycoprotein whilst exploiting identical monoclonal antibody-mAb [121]. Serum levels of CA125 are clinically utilized to diagnose OC patients on basis of regression or progression of the disease, subsequent to standard chemotherapy [122]. Moreover, abnormal mucin expression 
can trigger immunity and probably cause a strong antibody response. The antibody response is symptomatic of disease expression [123]. Immunoglobulin Ig (antibodies) affiliated with mucins, can have potential application in the progression towards the detection and therapy of ovarian cancer; however, there are still few studies conducted to date [121-123].

\section{Stimulus-Responsive Nanomicelles}

Stimuli-responsive nanomicelles (SRM) are smart nanoparticles engineered to respond to internal/ external stimuli of physical, chemical or biochemical origin, to control and release drug payloads at specific sites. SRM deliver drug payloads by structural alterations in response to the eliciting stimulus. The response presents with the degradation/disruption, polymerization or assembly of nanomicelles. The common internal stimuli in a cancer microenvironment are acidic $\mathrm{pH}$, electrochemical redox potentials of the cell, and the availability of certain over-produced matrix enzymes, while external stimuli include temperature, attraction via magnetic field, light illumination (UV, visible, infrared) and ultrasound waves [95]. In this context, the formulation of nanomicelle, sensitive to external or internal stimuli is an alternative approach to targeted therapeutic release. In vitro models have provided evidence of progress for a number of stimuli-responsive approaches, however only a small proportion have been validated in animal preclinical prototypes, and also few (thermosensitive liposomes and iron oxide nanoparticles) are clinically approved by the FDA in terms of treatments and diagnostics [81].

\section{Nanomicelles in Clinical Evaluations}

Several therapeutic-loaded nanomicelles for chemotherapy have been evaluated for determination of toxicity and bioavailability [124]. While the impetus is on ovarian cancer, some examples of polymeric nanomicelles cited are for other types of cancer and applied for OC treatment. Preclinical evaluations and findings have revealed lots of positive data utilizing nanomicelles as therapeutic delivery systems for loading hydrophobic chemotherapeutic drugs [125]. Several micellar nanoformulations that are now under clinical evaluations are all stealth nanomicelle formulations, and specifically have a surface coating for stabilization to guarantee a compact conformational covering and protection against opsonisation by plasma proteins (Table 4) [69]. Genexol-PM micelle formulation is paclitaxel-loaded PEG-PLA micelle preparation [126]. NK012 micellar nanoformulation is also composed of a PEG coating with amino-acid repeat units, polyglutamate (PGlu) combined with antineoplastic 7-ethyl-10-hydroxy-camptothecin (SN-38) [69]. The hydrophobic PGlu component results in micelle aggregation. In vivo trials with NK012 micelle formulations validated the potency of antineoplastic action in a mice model. Recently, the accomplishments and applicability of NK012 were also screened in phase II trials in prominent breast tumour patients [69]. New paclitaxel (PTX) experimental formulations evaluated include NK105 that are composed of PEG coating and modified polyaspartate hydrophobic ration [69]. PTX drug is incorporated in the central core by hydrophobic links with the hydrophilic portion. Furthermore, a major decrease in cytotoxicity, from Cremophor EL and ethanol subsequent to primary PTX administration, was practical with NK105. In phase I trials with NK105 formulation, minor allergic reactions were identified in patients with bile duct, pancreatic, gastric, and colonic cancers compared to primary PTX treatment [69]. 
Table 4. Polymeric micelle-based formulations containing chemotherapeutic drugs in clinical trials.

\begin{tabular}{|c|c|c|c|c|c|c|c|}
\hline $\begin{array}{c}\text { Formulation Trade } \\
\text { Name }\end{array}$ & Incorporated Drug & Purpose & Polymer & Particle Size (nm) & Drug Loading (\%) & Phase & References \\
\hline Genexol-PM & Paclitaxel & Solubilization & MPEG-PDLLA & $<50$ & 16.7 & III, IV & [127] \\
\hline NK-105 & Paclitaxel & Targeting & PEG-P(Asp) & 85 & 23.0 & II, III & [128] \\
\hline SP-1049C & Doxorubicin & Anti-MDR effect & Pluronic L61, F127 & 30 & 8.2 & I, II, III & [69] \\
\hline DTXL-TNP & Doxorubicin & Targeting & $\begin{array}{c}\text { PLA-PEG, } \\
\text { PLA-PEG-ACUPA }\end{array}$ & 100 & 10 & I & [129] \\
\hline NC-6004 & Cisplatin & Targeting & PEG-P(Glu)-Cisplatin & 30 & 39 & I, II & [130] \\
\hline NC-4016 & DACH-platin & Targeting & PEG-P(Glu)-DACH-platin & $20-100$ & 25 & I & [131] \\
\hline NK 012 & SN-38 & Targeting & PEG-P(Glu)-SN38 & 20 & 20.0 & II & [132] \\
\hline NK911 & Doxorubicin & Targeting & PEG-(Asp)-Dox & 40 & n. a & II & [133] \\
\hline
\end{tabular}


A SP1049C phase II cancer trial in cases with advanced stomach cancer has been conducted. SP1049C has been formulated as doxorubicin (DOX)-loaded Pluronic micelles [69]. In these phase II cancer trials, SP1049C displayed to be more effective than clinical doxorubicin in therapy of various types of carcinoma [69]. SP1049C displayed superior antineoplastic action, efficiency and increased in cancer cells in several pre-clinical carcinoma models as well as doxorubicin-resistant malignancies as compared to clinical doxorubicin [69]. SP1049C formulations have been screened in phase III trials in patients with metastatic adenocarcinoma of the gastrointestinal route [69]. To minimise toxicity and increase the efficacy of cisplatin, the micellar pharmaceutical preparation NC-6004 (Nanoplatin ${ }^{\mathrm{TM}}$ ) was developed. The NC-6004 consists of PEG coating with poly ( $\gamma$-benzyl L-glutamate)/CDDP composite [69]. A small phase I pilot showed that NC-6004 was acknowledged by carcinoma patients that were affected by colorectal carcinoma, upper oesophageal carcinoma, and lung carcinoma [69]. The Genexol-PM formulation was a micellar PTX nanoformulation formulated from PEG with polylactic acid $[68,134,135]$. Preclinical in vivo trials with Genexol-PM formulation exhibited a threefold increase in average dissolution time and a significantly improved antineoplastic efficacy as compared with clinical paclitaxel [69].

\section{Patents in Micellar Technologies for Targeted Chemotherapeutic Drug Delivery}

In a patent by Kwon and associates (2015), solubilisation of cotton gossypol (a yellow, natural phenolic aldehyde plant pigment for inhibition of various dehydrogenase enzymes) with nanomicelles was conducted. Polymeric-nanomicelles integrated chemodrugs such as gossypol, and a combination of chemodrugs were evaluated, including mixture of a platinum-derived (cisplatin-(CDDP) or carboplatin) as well as a taxane (paclitaxel (PTX) or docetaxel-(DTX)), commonly used to cure nonsmall cell-lung (NSCLC) and ovarian cancers. The nanomicelle carrier's composition enabled efficacious incorporation of the hydrophobic drugs [135-137]. Hence, this discovery provided stable and nontoxic biocompatible therapeutic formulations that potentially increased drug bioavailability. In another patent, nanomicelles encapsulating $\mathrm{SN}-38$ formulation for chemotherapy of carcinoma were investigated. This development provided a nanomicelle formulation, including extended multiblock co-polymer with a SN-38 resulting from encapsulated camptothecin [61,138]. This SN-38 formulation is dominant over its camptothecin derivative since it is not reliant on stimulation by the detoxifying liver in vivo (Table 5) [138].

Bodrati in 2018 demonstrated the application of block-co-polymer nanomicelle of poly(oxyethylene)-block-poly(oxypropylene) copolymer in the administration of chemotherapeutic agents, providing noncovalent dissolvation, which minimized solubility issues [61]. Several copolymers are readily obtainable under the generic name of "poloxamers"| "pluronics". Innovation by Hao et al. (2017) comprised of nanomicelle aggregates, composites with self-aggregated/assembled nanomicelles and methods for formulating nanomicelle aggregates and composites. Nanoformulation also included a plant prolamin proteins attached to polyethylene glycol (PEG)-coated nanomicelle [139]. This invention further derived methods for integration of drugs utilizing the conjugates of the protein nanomicelle formulation. In a patent by Rhymer (2008) micellar structures, techniques of micellar assemblies, methods of nanoimaging, approaches of chemotherapeutic delivery and life biological composites were investigated [140]. This patent presented a therapeutic technique utilizing hydrophilic, high molecular mass block copolymer for facilitation of an intraperitoneally dosed antineoplastic agent for prolonged release in the peritoneal region. The patent further described a therapeutic-loaded nanomicelle formulation, consisting of a copolymer with an exterior water-soluble moiety, a polycarboxylic acid functional group; and an anti-tumour agent attached to or incorporated in the nanomicelle. Patents in micellar technologies for antineoplastic drugs delivery are presented in Table 5. 
Table 5. Micellar patents issued in the area of cancer drug delivery (Adapted and modified from Mishra et al. [138]).

\begin{tabular}{|c|c|c|c|c|c|c|}
\hline Patent Type & Title & Patent No. & Chemical Formula & Action & Year & Inventor/Assignee \\
\hline Micelles & C6-c18-acylated derivative of hyaluronic acid & WO2014082609 A1 & $(\mathrm{HA})-[0(\mathrm{C}:=\mathrm{O}) \mathrm{NH}-\mathrm{M}]_{p}$ & $\mathrm{AC}$ & 2014 & Contipro Biotech S.R.O. \\
\hline Micelles & Polymer conjugated protein micelles & EP 2678001 A2 & PEG-Prolamine & $\mathrm{AC}$ & 2014 & $\begin{array}{l}\text { South Dakota State } \\
\text { University }\end{array}$ \\
\hline $\begin{array}{l}\text { Paclitaxel Micelle } \\
\quad \text { (NK105) }\end{array}$ & $\begin{array}{l}\text { Micellar preparation containing sparingly } \\
\text { water-soluble anticancer agent and novel } \\
\text { block copolymer }\end{array}$ & 09705599.0 & $\begin{array}{l}\text { (poly(ethylene glycol)-copoly } \\
\text { (L-aspartic acid) }\end{array}$ & $\mathrm{AC}$ & 2013 & $\begin{array}{l}\text { Nanocarrier Co. Ltd. } \\
\text { Nippon Kayaku Co., Ltd. }\end{array}$ \\
\hline Nanoplatin ${ }^{\circledR}$ (NC-6004) & Pharmaceutical composition and combined agent & 098101554 & $\begin{array}{l}\text { (poly(ethylene glycol)-copoly } \\
\text { (amino acid) }\end{array}$ & $\mathrm{AC}$ & 2013 & TOUDAI TLO Ltd. \\
\hline $\begin{array}{l}\text { DACH-Platin Micelle } \\
\text { (NC-4016) }\end{array}$ & $\begin{array}{c}\text { Coordination compound composed of } \\
\text { diaminocyclohexane platinum (Ii) and block copolymer }\end{array}$ & $2007-520209$ & $\begin{array}{l}\text { (poly(ethylene glycol)-copoly } \\
\text { (amino acid) }\end{array}$ & $\mathrm{AC}$ & 2013 & The University of Tokyo \\
\hline Protein Micelle & $\begin{array}{l}\text { Electrostatic bonding type macromolecular micelle } \\
\text { drug carrier }\end{array}$ & EP2583563 A1 & $\begin{array}{l}\text { polyethylene glycol and } \\
\text { poly }(\alpha,-\beta \text {-aspartic acid })\end{array}$ & $\mathrm{AC}$ & 2013 & TOUDAI TLO Ltd. \\
\hline siRNA Micelle & Polyethylene glycol/polycation block copolymer & EP2087912 A1 & PEG-PLys & $\mathrm{AC}$ & 2013 & The University of Tokyo \\
\hline Sensor Linked Micelle & $\begin{array}{l}\text { Active targeting polymer micelle encapsulating drug, } \\
\text { and pharmaceutical composition }\end{array}$ & $2008-539901$ & $\begin{array}{c}\text { poly(ethylene } \\
\text { glycol)-b-poly(2-aminoethyl } \\
\text { methacrylate)-b-poly(styrene) }\end{array}$ & $\mathrm{AC}$ & 2013 & Nanocarrier Co. Ltd. \\
\hline pH-Sensitive Micelle & $\begin{array}{l}\text { Novel block copolymer used for preparing } \\
\text { pH-responsive polymer micelles }\end{array}$ & 2009-7007877 & [PEG-p(Asp-Hyd-Adr)] & $\mathrm{AC}$ & 2013 & The University of Tokyo \\
\hline Docetaxel Micelle & $\begin{array}{l}\text { Docetaxel polymer derivative, method for producing } \\
\text { same and use of same }\end{array}$ & 2009250393 & (mPEG-PDLLA) & $\mathrm{AC}$ & 2013 & Nanocarrier Co. Ltd. \\
\hline Bortezomib Micelle & $\begin{array}{l}\text { Pharmaceutical composition that includes block } \\
\text { copolymer containing boronic acid compound }\end{array}$ & EP 2692777 A1 & $\begin{array}{c}\text { polyethylene } \\
\text { glycol-polyglutamic acid }\end{array}$ & $\mathrm{AC}$ & 2013 & Nanocarrier Co. Ltd. \\
\hline Micelles & Micelles for the solubilisation of gossypol & 20120321715 & Poloxamer or PEG-PCL & $\mathrm{AC}$ & 2012 & $\begin{array}{l}\text { Wisconsin Alumni Research } \\
\text { Foundation., US }\end{array}$ \\
\hline
\end{tabular}

Abbreviations: AC (Anticancer activity including ovarian cancer and various cancers such as lung and prostate cancer), MA Microaggregates), PEG/PEG 2000 (poly(ethylene glycol-2000),

Hyaluronic acid (HA), C = O (carbonyl group), -PLys (polylysine), Asp(Aspartate), Hyd-Adr(hydrazone Adriamycin, poly-DL-lactide (PDLLA), PCL(polycaprolactone). 


\section{Future Recommendations}

Nanomicelles are employed as drug carrier nanosystems or imaging agents. Extensive differentiation in physicochemical, pharmacological and immunological platforms is necessary prior to approval for application in humans. Antineoplastic efficacy of most chemotherapeutic nanoformulations has not advanced to an appropriate degree to evolve the formulated nanomedicines into clinical application. Thus, great research studies are conducted on optimization of physicochemical profiles of nanomicelles. Combinational chemotherapy against ovarian cancer is another approach used to enhance antineoplastic efficacy. Future trends in nanomicelle development and delivery includes circulatory computational evaluations, simulating ecosystems of the pathogens and patient-derived cell lines, induced pluripotent stem cell (iPSC) technology, three-dimensional coculture, organotypic systems, improvements in cell imaging, microfluidics, nanotechnologies and gene-editing technologies.

The main challenge is now linked with the interpretation of various productive and validated experimental findings into clinical translation. The efficacy of the therapeutics is limited due to degradation, interactions with cells, and poor tissue permeability. Furthermore, encapsulation of two or more therapeutics in a single nanocarrier system can be challenging due to different solubilities of the optimal drug combination. Nanotheranostics are therapeutics activated by a positive diagnosis of an ovarian cancer disease and will be in use in the near future for chemotherapeutics.

\section{Conclusions}

Novel nanomicellar technologies developed to date are focused on improving pharmacodynamics and pharmacokinetic profiles of the incorporated therapeutic agents, whilst increasing safety and compliance, to upsurge the five-year survival rate of OC patients. Nanomicellar systems have advanced as significant chemotherapeutic delivery platforms. These nanocarriers can be specifically loaded with a wide range of active drug compounds, providing a strategy to improve the bioavailability of drugs, including those abandoned due to insoluble characteristics and cytotoxicity challenges. Nanomicelles have also shown to be applicable for theranostic applications. Multipurpose polymeric nanomicelles have more attributes as therapeutic carriers, as shown by their considerable outcomes in the scope of clinical diagnosis and chemotherapeutics. These include nanomicelles attached with ligands, the enabling of specific active targeting of tumour metastasis, increased restorative effects, and reduced side effects-thus promoting more effective therapy. Although no panacea may be eminent at this time, it is anticipated that through tailored, safe, multifaceted, and rational design of nanomicelles, advanced drug delivery systems will be developed for the future treatment and diagnosis of OC.

Author Contributions: J.M.P., P.P.D.K., Y.E.C., T.M. and V.P. designed the framework and main content of the manuscript, further contributing to specific attributes on nanomedicine for ovarian chemotherapeutics. All authors have read and agreed to the published version of the manuscript.

Funding: This research was funded by National Research Foundation of South Africa.

Acknowledgments: This work was funded by the National Research Foundation (NRF) of South Africa.

Conflicts of Interest: The authors declare no conflict of interests.

\section{References}

1. Loret, N.; Denys, T.; Berx, G. The role of epithelial-to-mesenchymal plasticity in ovarian cancer progression and therapy resistance. Cancers 2019, 11, 838. [CrossRef] [PubMed]

2. Ghisoni, E.; Imbimbo, M.; Zimmermann, S.; Valabrega, G. Ovarian cancer immunotherapy: Turning up the heat. Int. J. Mol. Sci. 2019, 20, 2927. [CrossRef] [PubMed]

3. Deuster, E.; Mayr, D.; Hester, A.; Kolben, T.; Zeder-Göß, C.; Burges, A. Correlation of the aryl hydrocarbon receptor with fshr in ovarian cancer patients. Int. J. Mol. Sci. 2019, 20, 2862. [CrossRef] [PubMed]

4. Siu, K.Y.M.; Jiang, Y.; Wang, J.; Leung, T.H.Y.; Han, C.Y.; Benjamin, K. Hexokinase 2 regulates ovarian cancer cell migration, invasion and stemness via FAK/ERK1/2/MMP9/NANOG/SOX9 signaling cascades. Cancers 2019, 11, 813. [CrossRef] [PubMed] 
5. Garziera, M.; Roncato, R.; Montico, M.; De Mattia, E.; Gagno, S.; Poletto, E.; Cecchin, E. New challenges in tumor mutation heterogeneity in advanced ovarian cancer by a targeted next-generation sequencing (NGS) approach. Cells 2019, 8, 584. [CrossRef]

6. Wieser, V.; Sprung, S.; Tsibulak, I.; Haybaeck, J.; Hackl, H.; Fiegl, H. Clinical impact of RANK signalling in ovarian cancer. Cancers 2019, 11, 791. [CrossRef]

7. Menyhárt, O.; Fekete, J.T.; Gyorffy, B. Gene expression indicates altered immune modulation and signaling pathway activation in ovarian cancer patients resistant to Topotecan. Int. J. Mol. Sci. 2019, 20, 2750. [CrossRef]

8. Smith, T.; Guidozzi, F. Epithelial ovarian cancer in Southern Africa. SA J. Gynaecol. Oncol. 2009, 1, $23-27$. [CrossRef]

9. Erol, A.; Niemira, M.; Kretowski, A.D. Novel approaches in ovarian cancer research against heterogeneity, late diagnosis, drug resistance, and transcoelomic metastases. Int. J. Mol. Sci. 2019, 20, 2649. [CrossRef]

10. Maru, Y.; Hippo, Y. Current status of patient-derived ovarian cancer models. Cells 2019, 8, 505. [CrossRef]

11. Madariaga, A.; Lheureux, S.; Oza, A.M. Tailoring ovarian cancer treatment: Implications of BRCA1/2 mutations. Cancers 2019, 11, 416. [CrossRef]

12. Moffitt, L.; Karimnia, N.; Stephens, A.; Bilandzic, M. Therapeutic Targeting of Collective Invasion in Ovarian Cancer. Int. J. Mol. Sci. 2019, 20, 1466. [CrossRef] [PubMed]

13. Napoletano, C.; Ruscito, I.; Bellati, F.; Zizzari, I.G. Bevacizumab-based chemotherapy triggers immunological effects in responding multi-treated recurrent ovarian cancer patients by favoring the recruitment of effector $\mathrm{t}$ cell subsets. J. Clin. Med. 2019, 8, 380. [CrossRef] [PubMed]

14. Chishti, N.; Satveer Jagwani, S.; Dhamecha, D.; Jalalpure, S.; Dehghan, M.H. Preparation, optimization, and In Vivo Evaluation of nanoparticle-based formulation for pulmonary delivery of anticancer drug. Medicina 2019, 55, 294. [CrossRef] [PubMed]

15. Dlamini, N.G.; Basson, A.K.; Pullabhotla, V.S.R. Optimization and application of bioflocculant passivated copper nanoparticles in the wastewater treatment. Int. J. Environ. Res. Public Health 2019, 16, 2185. [CrossRef] [PubMed]

16. Cagliani, R.; Gatto, F.; Bardi, G. Protein adsorption: A feasible method for nanoparticle functionalization? Materials 2019, 12, 1991. [CrossRef]

17. Dong, X. Review on current strategies for brain drug delivery. Theranostics 2018, 8, 1481-1493. [CrossRef]

18. Basso, J.; Miranda, A.; Nunes, S.; Cova, T.; Sousa, J.; Vitorino, C.; Pais, A. Review on hydrogel-based drug delivery nanosystems for the treatment of brain tumors. MDPI J. Gels 2018, 4, 62. [CrossRef]

19. Blanco, E.; Kessinger, C.W.; Sumer, B.D.; Gao, J. Multifunctional micellar nanomedicine for cancer therapy. Exp. Biol. Med. 2009, 234, 123-131. [CrossRef]

20. Larraneta, E.; Stewart, S.; Ervine, M.; Al-Kasasbeh, R.; Donnelly, R.F. Hydrogels for hydrophobic drug delivery, classification, synthesis and applications. J. Funct. Biomater. 2018, 9, 13. [CrossRef]

21. Chirwa, N.; Pillay, V.; Choonara, Y.E.; Kumar, P.; du Toit, L. Pharmaceutical Composition. U.S. Patent 9220773 B2, 29 December 2015.

22. Vivek, R.; Thangam, R.; Kumar, S.R.; Rejeeth, C.; Kumar, G.S.; Sivasubramanian, S.; Vincent, S.; Gopi, D.; Kannan, S. HER2 targeted breast cancer therapy with switchable "off/on" multifunctional "smart" magnetic polymer core-shell nanocomposites. ACS Appl. Mater. Interfaces 2016, 8, 2262-2279. [CrossRef]

23. Fanshawe, T.R.; Power, M.; Graziadio, S.; Jones, W.; Ordonez-Mena, J.M.; Simpson, A.J.; Oxford, O. Methods for evaluation of medical prediction models, tests and biomarkers (MEMTAB) symposium. Diagn. Progn. Res. 2018, 2. [CrossRef]

24. Whitehouse, C.; Solomon, E. Current status of the molecular characterization of the ovarian cancer antigen CA125 and implications for its use in clinical screening. Gynaecol. Oncol. 2003, 88, 152-157. [CrossRef] [PubMed]

25. Yu, X.; Trase, I.; Ren, M.; Duval, K.; Guo, X.; Chen, Z. Design of nanoparticle-based carriers for targeted drug delivery. J. Nanomater. 2016, 2016, 1087250. [CrossRef] [PubMed]

26. Bhise, K.; Sau, S.; Alsaab, H.; Kashaw, S.K.; Tekade, R.K.; Iyer, A.K. Nanomedicine for cancer diagnosis and therapy, advancement, success and structure-activity relationship. Ther. Deliv. 2017, 8, 1003-1018. [CrossRef] [PubMed] 
27. Luong, D.; Sau, S.; Kesharwani, P.; Iyer, A.K. Polyvalent folate-dendrimer-coated iron oxide theranostic nanoparticles for simultaneous magnetic resonance imaging and precise cancer cell targeting. Biomacromolecules 2017, 18, 1197-1209. [CrossRef]

28. Sharma, A.K.; Gothwal, A.; Kesharwani, P.; Alsaab, H.; Iyer, A.K.; Gupta, U. Dendrimer nanoarchitectures for cancer diagnosis and anticancer drug delivery. Drug Discov. Today 2017, 22, 314-326. [CrossRef]

29. Chauhan, S.C.; Singh, A.P.; Ruiz, F.; Johansson, S.L.; Jain, M.; Smith, L.M.; Batra, S.K. Aberrant expression of MUC4 in ovarian modern pathology carcinoma, diagnostic significance alone and in combination with MUC1 and MUC16 (CA125). Mod. Pathol. 2006, 19, 1386-1394. [CrossRef] [PubMed]

30. Felder, M.; Kapur, A.; Gonzalez-Bosquet, J.; Horibata, S.; Heintz, J.; Albrecht, R.; Whelan, R.J. MUC16 (CA125), tumor biomarker to cancer therapy, a work in progress. J. Mol. Cancer 2014, 13, 129. [CrossRef] [PubMed]

31. Trucillo, P.; Campardelli, R.; Reverchon, E. Supercritical $\mathrm{CO}_{2}$ assisted liposomes formation: Optimization of the lipidic layer for an efficient hydrophilic drug loading. J. $\mathrm{CO}_{2}$ Util. 2017, 18, 181-188. [CrossRef]

32. Kue, C.S.; Kamkaew, A.; Burgess, K.; Kiew, L.V.; Chung, L.Y.; Lee, H.B. Small molecules for active targeting in cancer. Med. Res. Rev. 2016, 36, 494-575. [CrossRef] [PubMed]

33. Fathi, M.; SimaMajidi, S.; Zangabad, P.S.; Barar, J.H.E.; Omidi, Y. Chitosan- based multifunctional nanomedicines and theranostics for targeted therapy of cancer. Med. Res. Rev. 2018, 38, 2110-2136. [CrossRef] [PubMed]

34. Larsson, M.; Huang, W.C.; Hsiao, M.H.; Wang, Y.J.; Nydén, M.; Chiou, S.H.; Liu, D.M. Biomedical applications and colloidal properties of amphiphilically modified chitosan hybrids. Prog. Polym. Sci. 2013, 38, 1307-1328. [CrossRef]

35. Chen, H.P.; Chen, M.H.; Tung, F.I.; Liu, T.Y. A novel micelle-forming material used for preparing a theranostic vehicle exhibiting enhanced in vivo therapeutic efficacy. J. Med. Chem. 2015, 58, 3704-3719. [CrossRef] [PubMed]

36. Yu, F.; Jiang, F.; Tang, X.; Wang, B. N-octyl-N-arginine-chitosan micelles for gambogic acid intravenous delivery, characterization, cell uptake, pharmacokinetics, and biodistribution. Drug Dev. Ind. Pharm. 2018, 44, 615-623. [CrossRef] [PubMed]

37. Feng, S.; Li, J.; Luo, Y.; Yin, T.; Cai, H.; Wang, Y.; Dong, Z.; Shuai, X.; Li, Z. pH-Sensitive nanomicelles for controlled and efficient drug delivery to human colorectal carcinoma lovo cells. PLoS ONE 2014, 9, e100732. [CrossRef]

38. Kobayashi, H.; Watanabe, R.; Choyke, P.L. Improving conventional enhanced permeability and retention (EPR) effects; what is the appropriate target? Theranostics 2014, 4, 81-89. [CrossRef]

39. Nakamura, Y.; Mochida, A.; Choyke, P.L.; Kobayashi, H. Nanodrug delivery, is the enhanced permeability and retention effect sufficient for curing cancer? Bioconjug. Chem. 2016, 27, 2225-2238. [CrossRef]

40. Din, F.; Aman, W.; Ullah, I.; Qureshi, O.S.; Mustapha, O.; Shafique, S.; Zeb, A. Effective use of nanocarriers as drug delivery systems for the treatment of selected tumors. Int. J. Nanomed. 2017, 12, 7291-7309. [CrossRef]

41. Sutradhar, K.B.S.; Amin, M.L. Nanotechnology in cancer drug delivery and selective targeting. ISRN Nanotechnol. 2014, 939378-939389. [CrossRef]

42. Bolu, B.S.; Sanyal, M.R.; Sanyal, A. Drug delivery systems from self-assembly of dendron-polymer conjugates. Molecules 2018, 23, 1570. [CrossRef] [PubMed]

43. Macchione, M.A.; Biglione, C.; Strumia, M. Design, synthesis and architectures of hybrid nanomaterials for therapy and diagnosis applications. Polymers 2018, 10, 527. [CrossRef] [PubMed]

44. Senapati, S.; Mahanta, A.K.; Kumar, S.; Maiti, P. Controlled drug delivery vehicles for cancer treatment and their performance. Signal Transduct. Target. Ther. 2018, 3, 7. [CrossRef] [PubMed]

45. Atkinson, S.P.; Andreu, M.Z.; Vicent, M.J. Polymer therapeutics, biomarkers and new approaches for personalized cancer treatment. J. Pers. Med 2018, 8, 6 .

46. Dou, X.; Wang, H.; Zhang, J.; Wang, F.; Xu, G.; Xu, H.; Xiang, S.; Fu, J.; Song, H. Aptamer-Drug conjugate, targeted delivery of doxorubicin in a HER3 aptamer-functionalized liposomal delivery system reduces cardiotoxicity. Int. J. Nanomed. 2018, 13, 763-776. [CrossRef] [PubMed]

47. Lu, Y.; Park, K. Polymeric micelles and alternative nanonized delivery vehicles for poorly soluble drugs. Int. J. Pharm. 2012, 8, 1-17. [CrossRef]

48. Wang, J.; Yang, H. Superelastic and pH-responsive degradable dendrimer cryogels prepared by cryo-aza-michael addition reaction. Nat. Sci. Rep. 2018, 8, 7155. [CrossRef] 
49. Miao, T.; Wang, J.; Zeng, Y.; Liu, G.; Chen, X. Polysaccharide-based controlled release systems for therapeutics delivery and tissue engineering, from bench to bedside. Adv. Sci. 2018, 5, 1700513. [CrossRef]

50. Pelegri-O'Day, E.M.; Lin, E.; Maynard, H.D. Therapeutic protein-Polymer conjugates, advancing beyond PEGylation. J. Am. Chem. Soc. 2014, 136, 14323-14332. [CrossRef]

51. Brandta, J.V.; Piazzaa, R.D.; dos Santosa, C.C.; Vega-Chacóna, J.; Amantéaa, B.E. Synthesis and colloidal characterization of folic acid-modified PEG-b-PCL micelles for methotrexate delivery. Colloids Surf. B Biointerfaces 2019, 177, 228-234. [CrossRef]

52. Tong, R.; Yala, L.; Fan, T.M.; Cheng, J. The formulation of aptamer-coated paclitaxel-polylactide nanoconjugates and their targeting to cancer cells. J. Biomater. 2010, 31, 3043-3053. [CrossRef]

53. Huang, D.; Wu, D. Biodegradable dendrimers for drug delivery. Mater. Sci. Eng. C 2018, 90, 713-727. [CrossRef] [PubMed]

54. Lamichhane, N.; Udayakumar, T.S.; D'Souza, W.D.; Simone, M.I.I.; Charles, B.; Raghavan, S.R.; Mahmood, J.P. Liposomes: Clinical applications and potential for image-guided drug delivery. Molecules 2018, $23,288$. [CrossRef] [PubMed]

55. Fornaguera, C.; Dols-Perez, A.; Calderó, G.; García-Celma, M.J.; Camarasa, J.; Solans, C. PLGA nanoparticles prepared by nano-emulsion templating using low-energy methods as efficient nanocarriers for drug delivery across the blood-brain barrier. J. Control. Release 2015, 211, 134-143. [CrossRef] [PubMed]

56. Olusanya, T.O.B.; Ahmad, R.R.H.; Ibegbu, D.M.; Smith, J.R.; Elkordy, A.A. Liposomal drug delivery systems and anticancer drugs. Molecules 2018, 23, 907. [CrossRef]

57. Sercombe, L.; Veerati, T.; Moheimani, F.; Wu, S.Y.; Sood, A.K.; Hua, S. Advances and challenges of liposome assisted drug delivery. Front. Pharmacol. 2015, 6, 286. [CrossRef]

58. Lila, A.S.A.; Ishida, T. Liposomal delivery systems, design optimization and current applications. Biol. Pharm. Bull. 2017, 40, 1-10. [CrossRef]

59. Bhadani, A.; Kafle, A.; Koura, S.; Sakai, K.; Sakai, H.; Masahiko, A.M. Physicochemical evaluation of micellar solution and lyotropic phases formed by self-assembled aggregates of morpholinium geminis. ACS Omega 2017, 2, 5324-5334. [CrossRef]

60. Vaishya, R.D.; Khurana, V.; Patel, S.; Mitra, A.K. Controlled ocular drug delivery with nanomicelles. Wiley Interdiscip. Rev. Nanomed. Nanobiotechnol. 2014, 6, 422-437. [CrossRef]

61. Bodratti, A.M.; Alexandridis, P. Formulation of Poloxamers for Drug Delivery. J. Funct. Biomater. $2018,9,11$. [CrossRef]

62. Aziz, Z.A.A.; Ahmad, A.; Mohd-Setapar, S.H.; Hassan, H.; Lokhat, D.; Kamal, M.A.; Ashraf, M.G. Recent advances in drug delivery of polymeric nano-micelles. Curr. Drug Metab. 2017, 18, 16-29. [CrossRef] [PubMed]

63. Simões, S.M.N.; Figueiras, A.R.; Veiga, F.; Concheiro, A.; Alvarez-Lorenzo, C. Polymeric micelles for oral drug administration enabling locoregional and systemic treatments. Expert Opin. Drug Deliv. 2014, 12, 297-318. [CrossRef] [PubMed]

64. Movassaghian, S.; Merkel, O.M.; Torchilin, V.P. Applications of polymer micelles for imaging and drug delivery. Wiley Interdiscip. Rev. Nanomed. Nanobiotechnol. 2015, 7, 691-707. [CrossRef] [PubMed]

65. Vyas, B.; Pillai, S.A.; Bahadur, A.; Bahadur, P. A comparative study on micellar and solubilizing behavior of three eo-po based star block copolymers varying in hydrophobicity and their application for the In Vitro release of anticancer drugs. Polymers 2018, 10, 76. [CrossRef]

66. Santos, M.S.; Tavares, F.W.; Biscaia, E.C. Molecular Thermodynamics of micellization, micelle size distributions and geometry transitions. Braz. J. Chem. Eng. 2016, 33, 515-523. [CrossRef]

67. Chidi, O.; Adebayo, I.V. Determination of Critical Micelle Concentration and Thermodynamic Evaluations of Micellization of GMS. Mod. Chem. Appl. 2018, 6, 2. [CrossRef]

68. Mukherjee, I.; Moulik, S.P.; Rakshit, A.K. Tensiometric determination of Gibbs surface excess and micelle point: A critical revisit. J. Colloid Interface Sci. 2013, 394, 329-336. [CrossRef]

69. Sutton, D.; Nasongkla, N.; Blanco, E.; Gao, J. Functionalized micellar systems for cancer targeted drug delivery. Pharm. Res. 2007, 24, 1029-1046. [CrossRef]

70. Nguyen, V.T.A.; De Pauw-Gillet, M.; Sandre, O.; Gauthier, M. Biocompatible polyion complex micelles synthesized from arborescent polymers. langmuir. Am. Chem. Soc. 2016, 32, 13482-13492.

71. Hussein, Y.H.A.; Youssry, M. Polymeric micelles of biodegradable diblock copolymers, enhanced encapsulation of hydrophobic drugs. Materials 2018, 11, 688. [CrossRef] 
72. Ding, J.; Chen, L.; Xiao, C.; Chen, L.; Zhuang, X.; Chen, X. Noncovalent interaction-assisted polymeric micelles for controlled drug delivery. Chem. Commun 2014, 50, 11274-11290. [CrossRef] [PubMed]

73. Mandala, A.; Bisht, R.; Rupenthal, I.D.; Mitraa, A.K. Polymeric micelles for ocular drug delivery, From structural frameworks to recent preclinical studies. J. Control. Release 2017, 248, 96-116. [CrossRef] [PubMed]

74. Michalicova, P.; Mravec, F.; Peka, R.M. Fluorescence study of freeze-drying as a method for support the interactions between hyaluronic and hydrophobic species. PLoS ONE 2017, 12, e0184558. [CrossRef] [PubMed]

75. Rosenblum, D.; Josh, N.; Tao, W.; Karp, J.M.; Peer, D. Progress and challenges towards targeted delivery of cancer therapeutics. Nat. Commun. 2018, 9, 1410. [CrossRef]

76. Desai, K.G.H. Polymeric drug delivery systems for intraoral site-specific chemoprevention of oral cancer. J. Biomed. Mater. Res. Part B 2018, 106, 1383-1413. [CrossRef]

77. Hekman, M.C.H.; Boerman, O.C.; Bos, D.L.; Massuger, L.F.A.G.; Weil, S.; Grasso, L.; Rybinski, K.A.; Oosterwijk, E.; Mulders, P.F.A.; Rijpkema, M. Improved intraoperative detection of ovarian cancer by folate receptor alpha targeted dual-modality imaging. Mol. Pharm. 2017, 14, 3457-3463. [CrossRef]

78. Judy, R.P.; Keating, J.J.; DeJesus, E.M.; Jiang, J.X.; Okusanya, O.T.; Nie, S.; Singhal, S. Quantification of tumor fluorescence during intraoperative optical cancer imaging. Sci. Rep. 2015, 5, 16208. [CrossRef]

79. Jung, K.H.; Lee, K.H. Molecular imaging in the era of personalized medicine. J. Pathol. Transl. Med. 2015, 49, 5-12. [CrossRef]

80. Kedar, U.; Shidhaye, S.; Kadam, V.U. Advances in polymeric micelles for drug delivery and tumour targeting. Nanomed. Nanotechnol. Biol. Med. 2010, 6, 714-729. [CrossRef]

81. Chen, Y.; Lo, C.; Hsiue, G. Multifunctional nanomicellar systems for delivering anticancer drugs. J. Biomed. Mater. Res. Part A 2014, 102, 2024-2038. [CrossRef]

82. Harada, A.; Kataoka, K. Formation of polyion complex micelles in an aqueous milieu from a pair of oppositely-charged block copolymers with poly (ethylene glycol) segments. Macromolecules 1995, 28, 5294-5299. [CrossRef]

83. Li, Y.; Kwon, G.S. Methotrexate esters of poly (ethylene oxide)-block-poly(2-hydroxyethyl-l-aspartamide). Part I: Effects of the level of methotrexate conjugation on the stability of micelles and on drug release. Pharm. Res. 2000, 17, 607-611. [CrossRef] [PubMed]

84. Lavasanifar, A.; Samuel, J.; Kwon, G.S. Micelles self-assembled from poly (ethylene oxide)-block-poly (N-hexyl stearate l-aspartamide) by a solvent evaporation method: Effect on the solubilization and haemolytic activity of amphotericin B. J. Control. Release 2001, 77, 155-160. [CrossRef]

85. Kim, J.H.; Emoto, K.; Iijima, M.; Nagasaki, Y.; Aoyagi, T.; Okano, T.Y. Core-stabilized polymeric micelle as potential drug carrier: Increased solubilization of taxol. Polym. Adv. Technol. 1999, 10, 647-654. [CrossRef]

86. Zhiang, J.; Wu, M.; Yang, J.; Wu, Q.; Jin, Z. Anionic poly (lactic acid)-polyurethane micelles as potential biodegradable drug delivery carriers. Colloids Surf. A 2009, 337, 200-204. [CrossRef]

87. Patil, Y.B.; Toti, U.S.; Khdair, A.; Linan, M.; Panyam, J. Single-step surface functionalization of polymeric nanoparticles for targeted drug delivery. Biomaterials 2009, 30, 859-866. [CrossRef]

88. Chung, J.E.; Yokoyama, M.; Okano, T.; Yamato, M.; Aoyagi, T.; Sakurai, Y. Thermoresponsive drug delivery from polymeric micelles constructed using block copolymer of poly( $\mathrm{N}$-isopropylacrylamide) and poly (butyl methacrylate). J. Control. Release 1999, 62, 115-127. [CrossRef]

89. Elliott, R.L.; Elliott, M.C.; Wang, F.; Head, J.F. Breast carcinoma and the role of iron metabolism: A cytochemical, tissue culture and ultrastructural study. Ann. N.Y. Acad. Sci. 1993, 698, 159-166. [CrossRef]

90. Yamamoto, Y.; Nagasaki, Y.; Kato, Y.; Sugiyama, Y.; Kataoka, K. Longcirculating poly (ethylene glycol)-poly (D, L-lactide) block copolymer micelles with modulated surface charge. J. Control. Release 2001, 77, 27-38. [CrossRef]

91. Guo, J.; Gao, X.; Su, L.; Xia, H.; Gu, G.; Pang, Z.; Jiang, X.; Yao, L.; Chen, J.; Chen, H. Aptamer-functionalized PEG-PLGA nanoparticles for enhanced anti-glioma drug delivery. Biomaterials 2011, 32, 8010-8020. [CrossRef]

92. Yáñez, J.; Forrest, M.; Ohgami, Y.; Kwon, G.; Davies, N. Pharmacometrics and delivery of novel nanoformulated PEG-b-poly (E-caprolactone) micelles of rapamycin. Cancer Chemother. Pharmacol. 2008, 61, 133-144. [CrossRef] [PubMed]

93. Kim, D.; Lee, E.S.; Oh, K.T.; Gao, Z.G.; Bae, Y.H. Doxorubicin-loaded polymeric micelle overcomes multidrug resistance of cancer by double-targeting folate receptor and early endosomal pH. Small 2008, 4, 2043-2050. [CrossRef] [PubMed] 
94. Johnson, R.P.; Jeong, Y.I.; Choi, E.; Chung, C.W.; Kang, D.H.; Oh, S.O.; Suh, H.; Kim, I. Biocompatible poly (2-hydroxyethyl methacrylate)-bpoly (L-histidine) hybrid materials for $\mathrm{pH}$-sensitive intracellular anticancer drug delivery. Adv. Funct. Mater. 2011, 22, 1058-1068. [CrossRef]

95. Tsai, H.C.; Tsai, C.H.; Lin, S.Y.; Jhang, C.R.; Chiang, Y.S.; Hsiue, G.H. Stimulated release of photosensitizers from graft and diblock micelles for photodynamic therapy. Biomaterials 2012, 33, 1827-1837. [CrossRef]

96. Lu, P.L.; Chen, Y.C.; Ou, T.W.; Chen, H.H.; Tsai, H.C.; Wen, C.J.; Lo, C.L.; Wey, S.P.; Lin, K.J.; Yen, T.C.; et al. Multifunctional hollow nanoparticles based on graft-diblock copolymers for doxorubicin delivery. Biomaterials 2011, 32, 2213-2221. [CrossRef]

97. Lin, S.Y.; Hsu, W.H.; Lo, J.M.; Tsai, H.C.; Hsiue, G.H. Novel geometry type of nanocarriers mitigated the phagocytosis for drug delivery. J. Control. Release 2011, 154, 84-92. [CrossRef] [PubMed]

98. Cholkar, K.; Patel, A.; Vadlapudi, A.D.; Ashim, K.; Mitra, A.K. Novel nanomicellar formulation approaches for anterior and posterior segment ocular drug delivery. Recent Pat. Nanomed. 2012, 2, 82-95. [CrossRef]

99. Fares, A.R.; ElMeshad, A.N.; Kassem, M.A. Enhancement of dissolution and oral bioavailability of lacidipine via pluronic P123/ F127 mixed polymeric micelles, formulation, optimization using central composite design and in vivo bioavailability study. Drug Deliv. 2018, 25, 132-142. [CrossRef]

100. Vadlapudi, A.D.; Cholkar, K.; Vadlapatla, R.K.; Mitra, A.K. Aqueous nanomicellar formulation for topical delivery of biotinylated lipid prodrug of acyclovir, formulation development and ocular biocompatibility. J. Ocul. Pharmacol. Ther. 2014, 30,49-58. [CrossRef]

101. Lengyel, E. Ovarian cancer development and metastasis. Am. J. Pathol. 2010, 177, 1053-1064. [CrossRef]

102. Testa, U.; Petrucci, E.; Pasquini, L.; Castelli, G.; Pelosi, E. Ovarian cancers, genetic abnormalities, tumor heterogeneity and progression, clonal evolution and cancer stem cells. Medicines 2018, 5, 16. [CrossRef] [PubMed]

103. Lorenzo, G.D.; Ricci, G.; Severini, G.M.; Romano, F.; Biffi, S. Imaging and therapy of ovarian cancer, clinical application of nanoparticles and future perspectives. Theranostics 2018, 8, 16. [CrossRef] [PubMed]

104. Wright, A.A.; Cronin, A.; Milne, D.E.; Bookman, M.A.; Burger, R.A.; Cohn, D.E.; Mantia-Smaldone, G. Use and effectiveness of intraperitoneal chemotherapy for treatment of ovarian cancer. J. Clin. Oncol. 2015, 33, 2841-2847. [CrossRef] [PubMed]

105. Coward, J.I.G.; Middleton, K.; Murphy, F. New perspectives on targeted therapy in ovarian cancer. Int. J. Women's Health 2015, 7, 189-203. [CrossRef]

106. Jahangirian, H.; Lemraski, E.G.; Webster, T.J.; Moghaddam, R.; Abdollahi, Y. A review of drug delivery systems based on nanotechnology and green chemistry, green nanomedicine. Int. J. Nanomed. 2017, 12, 2957-2978. [CrossRef]

107. Fang, J.; Nakamura, H.; Maeda, H. The EPR effect, unique features of tumor blood vessels for drug delivery, factors involved, and limitations and augmentation of the effect. Adv. Drug Deliv. Rev. 2011, 63, 136-151. [CrossRef]

108. Makhmalzade, B.S.; Chavoshy, F. Polymeric micelles as cutaneous drug delivery system in normal skin and dermatological disorders. J. Adv. Pharm. Technol. Res. 2017, 9, 2-8.

109. Jahan, S.T.; Sam, M.A.; Walliser, M.; Haddadi, A. Targeted therapeutic nanoparticles, an immense promise to fight against cancer. Hindawi J. Drug Deliv. 2017, 2017, 9090325. [CrossRef]

110. Dai, L.; Liu, J.; Luo, Z.; Li, M.; Cai, K. Tumor therapy, targeted drug delivery systems. J. Mater. Chem. B. 2016, 4, 6758. [CrossRef]

111. Pillai, G. Nanomedicines for cancer therapy, an update of FDA approved and those under various stages of development. SOJ Pharm Pharm Sci. 2014, 1, 13.

112. Ljubimova, J.Y.; Sun, T.; Mashouf, L.; Ljubimov, A.V.; Israel, L.L.; Ljubimov, V.A.; Holler, E. Covalent nano delivery systems for selective imaging and treatment of brain tumours. Adv. Drug Deliv. Rev. 2017, 113, 177-200. [CrossRef] [PubMed]

113. Savla, R.; Minko, T. Nanoparticle design considerations for molecular imaging of apoptosis, diagnostic, prognostic, and therapeutic value. Adv. Drug Deliv. Rev. 2017, 113, 122-140. [CrossRef] [PubMed]

114. Estelrich, J.; Busquets, M.A.; Morán, M.C. Effect of pegylation on ligand-targeted magnetoliposomes, a missed goal. ACS Omega 2017, 2, 6544-6555. [CrossRef] [PubMed]

115. Gomes de Castro, M.A.; Ho bartner, C.; Opazo, F. Aptamers provide superior stainings of cellular receptors studied under super resolution microscopy. PLoS ONE 2017, 12, e0173050. [CrossRef] [PubMed] 
116. Cha, H.; Song, K.S. Effect of MUC8 on airway Inflammation: A friend or a foe? J. Clin. Med. 2018, 7, 26. [CrossRef] [PubMed]

117. Sudimack, B.A.J.; Lee, R.J. Targeted drug delivery via the folate receptor. J. Adv. Drug Deliv. Rev. 2013, 41, 147-162. [CrossRef]

118. Liao, C.; Sun, Q.; Liang, B.; Shena, J.; Shuai, X. Targeting EGFR-overexpressing tumour cells using Cetuximab-immunomicelles loaded with doxorubicin and superparamagnetic iron oxide. Eur. J. Radiol. 2010, 80, 699-705.

119. Das, S.; Batra, S.K. Understanding the unique attributes of MUC16 (CA125), potential implications in targeted therapy. Cancer Res. 2015, 75, 4669-4674. [CrossRef]

120. Rao, T.D.; Fernández-Tejada, A.; Axelrod, A.; Rosales, N.; Yan, X.; Thapi, S.; Lewis, J.S. Antibodies against Specific MUC16 glycosylation sites inhibit ovarian cancer growth. ACS Chem. Biol. 2017, 12, 2085-2096. [CrossRef]

121. Schummer, M.; Thorpe, J.; Giraldez, M.; Bergan, L.; Tewari, M.; Urban, N. Evaluating serum markers for hormone receptor-negative breast cancer. PLOS ONE 2015, 10, e0142911. [CrossRef]

122. Kabel, A.M. Tumour markers of breast cancer: New prospective. J. Oncol. Sci. 2017, 3, 5-11.

123. Mai, B.T.; Fernandes, S.; Balakrishnan, P.B.; Pellegrino, T. Nanosystems based on magnetic nanoparticles and thermos-or ph-responsive polymers: An update and future perspectives. Acc. Chem. Res. 2018, 51, 999-1013. [CrossRef] [PubMed]

124. Naseem, S.; Bansal, N.; Logani, L.A. Recent advances in imaging technologies in dentistry. World J. Radiol. 2014, 6, 794-807.

125. Singh, A.P.; Senapati, S.; Ponnusamy, M.P.; Jain, M.; Lele, S.M.; Davis, J.S.; Batra, S.K. Clinical potential of mucins in diagnosis, prognosis, and therapy of ovarian cancer. Lancet Oncol. 2008, 9, 1076-1085. [CrossRef]

126. Bansal, K.K.; Gupta, J.; Rosling, A.; Rosenholm, J.M. Renewable poly ( $\delta$-decalactone) based block copolymer micelles as drug delivery vehicle: In Vitro and In Vivo evaluation. Saudi Pharm. J. 2018, 26, 358-368. [CrossRef]

127. Lee, K.S.; Chung, H.C.; Im, S.A.; Park, Y.H.; Kim, C.S.; Kim, S.B. Multicenter phase II trial of genexol-PM, a cremophor-free, polymeric micelle formulation of paclitaxel, in patients with metastatic breast cancer. Breast Cancer Res. Treat. 2008, 108, 241-250. [CrossRef]

128. Matsumura, Y. Poly (amino acid) micelle nanocarriers in preclinical and clinical studies. Adv. Drug Deliv. Rev. 2008, 60, 899-914. [CrossRef]

129. Hrkach, J.; Von Hoff, D.; Mukkaram, A.M.; Andrianova, E.; Auer, J.; Campbell, T. Preclinical development and clinical translation of a PSMA-targeted docetaxel nanoparticle with a differentiated pharmacological profile. Sci. Transl. Med. 2012, 4, 128ra39. [CrossRef]

130. Wilson, R.H.; Plummer, R.; Adam, J.; Eatock, M.; Boddy, A.V.; Griffin, M. Phase I and pharmacokinetic study of NC-6004, a new platinum entity of cisplatin-conjugated polymer forming micelles. J. Clin. Oncol. 2008, 26, 2573. [CrossRef]

131. Ueno, T.; Endo, K.; Hori, K.; Ozaki, N.; Tsuji, A.; Kondo, S.; Yoshizaki, T. Assessment of antitumor activity and acute peripheral neuropathy of 1,2-diaminocyclohexane platinum (II)-incorporating micelles (NC-4016). Int. J. Nanomed. 2014, 9, 3005-3012. [CrossRef]

132. Matsumura, Y.; Kataoka, K. Preclinical and clinical studies of anticancer agent-incorporating polymer micelles. Cancer Sci. 2009, 100, 572-579. [CrossRef] [PubMed]

133. Matsumura, Y.; Hamaguchi, T.; Ura, T.; Muro, K.; Yamada, Y.; Shimada, Y.; Watanabe, N. Phase I clinical trial and pharmacokinetic evaluation of NK911, a micelle-encapsulated doxorubicin. Br. J. Cancer 2004, 91, 1775-1781. [CrossRef] [PubMed]

134. Xin, Y.; Yin, M.; Zhao, L.; Meng, F.; Luo, L. Recent progress on nanoparticle-based drug delivery systems for cancer therapy. Cancer Biol. Med. 2017, 14, 228-241. [CrossRef] [PubMed]

135. Kanwal, M.; Ding, X.; Song, X.; Zhou, G.; Cao, Y. MUC16 overexpression induced by gene mutations promotes lung cancer cell growth and invasion. Oncotarget 2018, 9, 12226-12239. [CrossRef] [PubMed]

136. Kwon, G.S.; Tomoda, K.; Chiang, C.; Kozak, K.R. Examination of gossypol-pluronic micelles as potential radiosensitizers. AAPS J. 2015, 17, 1369-1375.

137. Siraj, N.; El-Zahab, B.; Hamdan, S.; Karam, T.E.; Haber, L.H.; Li, M.; Patonay, G. Fluorescence, phosphorescence, and chemiluminescence. Anal. Chem. 2016, 88, 170-202. [CrossRef] [PubMed] 
138. Mishra, B.; Patel, B.B.; Tiwari, S. Colloidal nanocarriers: a review on formulation technology, types and applications toward targeted drug delivery. Nanomedicine 2010, 6, 9-24. [CrossRef]

139. Hao, J.; Tong, T.; Jin, K.; Zhuang, Q.; Han, T.; Bi, Y.; Wang, J.; Wang, X. Folic acid-functionalized drug delivery platform of resveratrol based on Pluronic 127/D- $\alpha$-tocopheryl polyethylene glycol $1000 \mathrm{~s}$ uccinate mixed micelles. Int. J. Nanomed. 2017, 12, 2279-2292. [CrossRef]

140. Rhyner, M.N. Development of Cancer Diagnostics Using Nanoparticles and Amphiphilic Polymers. Ph.D. Thesis, Georgia Institute of Technology, Atlanta, GA, USA, 2008.

C 2020 by the authors. Licensee MDPI, Basel, Switzerland. This article is an open access article distributed under the terms and conditions of the Creative Commons Attribution (CC BY) license (http://creativecommons.org/licenses/by/4.0/). 